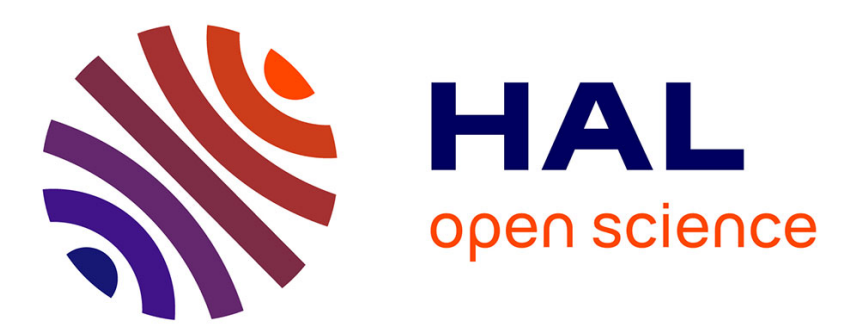

\title{
Assessing the Equalizing Force of Mobility Using Short Panels: France, 1990-2000
}

Stéphane Bonhomme, Jean-Marc Robin

\section{To cite this version:}

Stéphane Bonhomme, Jean-Marc Robin. Assessing the Equalizing Force of Mobility Using Short Panels: France, 1990-2000. Review of Economic Studies, 2009, 76, pp.63-92. hal-01027423

\section{HAL Id: hal-01027423 \\ https://hal-sciencespo.archives-ouvertes.fr/hal-01027423}

Submitted on 22 Dec 2014

HAL is a multi-disciplinary open access archive for the deposit and dissemination of scientific research documents, whether they are published or not. The documents may come from teaching and research institutions in France or abroad, or from public or private research centers.
L'archive ouverte pluridisciplinaire HAL, est destinée au dépôt et à la diffusion de documents scientifiques de niveau recherche, publiés ou non, émanant des établissements d'enseignement et de recherche français ou étrangers, des laboratoires publics ou privés. 


\title{
Assessing the Equalizing Force of Mobility Using Short Panels: France, 1990-2000
}

\author{
STÉPHANE BONHOMME \\ Centro de Estudios Monetarios y Financieros (CEMFI) \\ and \\ JEAN-MARC ROBIN \\ Paris School of Economics, Université Paris I Panthéon Sorbonne and \\ University College London
}

First version received July 2005; final version accepted May 2008 (Eds.)

\begin{abstract}
In this paper, we document whether and how much the equalizing force of earnings mobility has changed in France in the 1990's. For this purpose, we use a representative three-year panel, the French Labour Force Survey. We develop a model of earnings dynamics that combines a flexible specification of marginal earnings distributions (to fit the large cross-sectional dimension of the data) with a tight parametric representation of the dynamics (adapted to the short time-series dimension). Log earnings are modelled as the sum of a deterministic component, an individual fixed effect and a transitory component which is assumed first-order Markov. The transition probability of the transitory component is modelled as a one-parameter Plackett copula. We estimate this model using a sequential expectation-maximization algorithm.

We exploit the estimated model to study employment/earnings inequality in France over the 19902002 period. We show that, in phase with business-cycle fluctuations (a recession in 1993 and two peaks in 1990 and 2000), earnings mobility decreases when cross-section inequality and unemployment risk increase. We simulate individual earnings trajectories and compute present values of lifetime earnings for various horizons. Inequality presents a hump-shaped evolution over the period, with a $9 \%$ increase between 1990 and 1995 and a decrease afterwards. Accounting for unemployment yields an increase of $11 \%$. Moreover, this increase is persistent, as it translates into a $12 \%$ increase in the variance of log present values. The ratio of inequality in present values to inequality in one-year earnings, a natural measure of immobility or of the persistence of inequality, remains remarkably constant over the business cycle.
\end{abstract}

\section{INTRODUCTION}

It is generally agreed that measuring earnings dispersion in one single year does not provide an accurate picture of earnings inequality because forward-looking consumers can smooth transitory earnings shocks to some extent. The economist interested in measuring interpersonal differences in well-being can proceed in at least three ways: by studying consumption inequality directlybut the scarcity of consumer panels renders this approach difficult to implement in practice; ${ }^{1}$ by emulating consumer behaviour and studying individual differences in long-run earnings averages (usually, five- or ten-year means); or by decomposing individual earnings dynamics into persistent and transitory components.

1. Yet see Cutler and Katz (1992), Attanasio and Davis (1996), Blundell and Preston (1998), and Krueger and Perri (2001). 
The usual distinction between longer-run earnings inequality and earnings instability, or between persistent and transitory inequality, is at the heart of the approach theoretized by Shorrocks (1978), which measures mobility by comparing the inequality in multi-year earnings averages and annual earnings inequality. ${ }^{2}$ However, in a changing macroeconomic environment it is difficult to separate persistent inequality from transitory fluctuations. For this reason, several authors have recently proposed to replace actual means by simulated means calculated on artificial data generated using a parameterized model. The model is either estimated on a short period supposed to be approximately stable (Flinn, 2002; Bowlus and Robin, 2004), or on a longer period if the model specification encompasses both individual dynamics and structural change (Haider, 2001). ${ }^{3}$ In both cases, for a given year, longer-run measures of earnings are calculated holding structural parameters constant at the level of that particular year. This allows documentation of changes in the persistence of inequality — and the equalizing force of mobility—over time.

In this paper, we follow the literature and model log earnings as the sum of two factors, an individual-specific fixed effect and a stationary stochastic component, with time-varying factor loadings. ${ }^{4}$ However, while the literature essentially focuses on first- and second-order moments, we aim at modelling the entire multivariate distribution of earnings in the most flexible way possible. Given an estimate of the full distribution, we are then able to simulate earnings trajectories and compute longer-run measures of inequality. Our model is designed to fit the French Labour Force Survey (LFS), a sequence of 11 large three-year panels from 1990-1992 to 2000-2002. Contrary to other well-used panels like the Panel study of Income Dynamics (PSID), labour force surveys such as the Survey of Income and Program Participation (SIPP), for example, typically follow large samples of individuals over short periods of time. The model therefore combines a flexible specification of marginal earnings distributions - to fit the large cross-sections-with a tight parametric specification of the dynamics - adapted to the small time-series dimension.

The distribution of the individual effect is assumed discrete with many support points. This allows us to use a simple expectation-maximization (EM) algorithm for estimation, the EM algorithm being particularly well suited to the estimation of discrete mixtures. The marginal density of the transitory component is a normal mixture, and in order to map the marginals into the joint distribution of couples of consecutive realizations we use a parametric copula. We find that Plackett (1965) one-parameter copula captures the year-to-year dynamics quite well. We also model transitions between employment and unemployment by a Markov chain that is conditional on the fixed effect.

The model being non-identified when factor loadings are allowed to vary freely over time, we assume that they vary sufficiently slowly and smoothly for each three-year panel to face a specific set of time-invariant factor loadings. For each three-year panel, the model thus takes the form of a mixture of non-linear first-order Markov models. The non-linearity renders identification difficult to characterize in a simple way. We, nevertheless, provide a set of functional restrictions under which the distributions of the fixed effect and the transitory shocks are non-parametrically identified. Identification holds assuming the injectivity of two non-linear operators. These

2. Moffitt and Gottschalk (2002) claim that five years is the minimal number of years for averaging earnings. "A shorter lag would [give] a more distorted picture of the growth of permanent variances because short lags would be contaminated by increasing transitory variances" (p. C72). For recent applications of this technique, see, for example, Burkhauser, Holtz-Eakin and Rhody (1997), Burkhauser and Poupore, (1997), Maasoumi and Trede (2001), Aaberge, Bjørklund, Jäntti, Palme, Pedersen, Smith and Wennemo (2002), and Van Kerm (2004).

3. Other examples of models of earnings dynamics with time-varying parameters can be found in Moffitt and Gottschalk (2002), Heathcote, Storesletten and Violante (2004), Meghir and Pistaferri (2004), Baker and Solon (2003), and Guvenen (2007).

4. Thus, unlike Flinn (2002) and Bowlus and Robin (2004) our modelling allows for unobserved heterogeneity (permanent components) in earnings. 
assumptions, as in most inverse problems, cannot be translated into simple properties of the data-generating process.

Our model is closely related to Geweke and Keane (2000) first-order autoregressive model with an individual-specific drift and another AR(1) transitory component. They adopt a flexible specification (normal mixtures) for the distributions of transitory shocks. ${ }^{5}$ By comparison, our model has a more constrained dynamic structure that is adapted to very short panels. On the other hand, Geweke and Keane estimate a stationary model using 20 years of PSID data (1968-1989), while our framework allows parameters to change with the business cycle.

We start by documenting changes in earnings inequality, and in earnings and employment mobility in France in the 1990's. We show that the first half of the period is characterized by a simultaneous increase in earnings inequality, earnings immobility, and unemployment risk, and the second half by a symmetrical decrease. As 1988-1990 and 1998-2000 correspond to periods of fast growth and 1993 to a recession, business-cycle conditions appear strongly associated with individual earnings dynamics. This structural instability justifies a model of individual earnings dynamics with time-varying parameters. We then use the estimated model to simulate individual trajectories for each year of the 1990 decade and compute measures of inequality of present values (PVs) of earnings sequences of various lengths. Finally, by computing the ratio of the inequality in PVs to earnings inequality in one cross-section, we document how the equalizing force of mobility changed in the 1990's.

We find that the permanent component (fixed effect) has a nearly Gaussian distribution. The marginal distribution of the transitory component is leptokurtic, large shocks being much more probable than for a normal distribution. Unemployment is an important source of inequality. The variance of log monthly earnings increases by 9\% between 1990 and 1995 and decreases afterwards. In contrast, imputing Unemployment Insurance (UI) benefits to unemployed workers using a replacement ratio of $60 \%$, the variance of log income in the whole sample increases by $11 \%$ between 1990 and 1995 . Moreover, this increase is persistent as the variance of the log PVs of lifetime earnings also increases by $12 \%$ in the same period, before decreasing at the end of that period. Lastly, the equalizing force of mobility changed remarkably little over the period.

The remainder of the paper is organized as follows. Section 2 precisely describes the model, and Section 3 discusses its identification. Section 4 presents the data. Section 5 describes the estimation method and presents parameter estimates, and Section 6 shows how the model fits the data. Section 7 shows the main results of the paper, comparing cross-sectional and longer-run earnings inequality in France in the 1990's. Section 8 provides some model comparison exercises. The last section concludes.

\section{A MODEL OF EARNINGS DYNAMICS FOR SEQUENCES OF LARGE, SHORT PANELS}

We consider a series of short panel datasets $\mathcal{S}_{j}, j=1, \ldots, J$, with many individual observations. Each subpanel $\mathcal{S}_{j}$ records individual log earnings $y_{i t}$ and individual attributes $x_{i t}$ over a fixed time length $T$ :

$$
\mathcal{S}_{j}=\left\{\left(y_{i t}, x_{i t}\right), i=1, \ldots, N, t=t_{j}, t_{j}+1, \ldots, t_{j}+T-1\right\},
$$

where $t_{j}$ denotes the first observation date for panel $\mathcal{S}_{j}$. So $t_{j}$ represents the time at which individuals in $\mathcal{S}_{j}$ enter the panel. For example, the LFS is a sequence of overlapping three-year panels $(T=3)$.

5. Geweke and Keane (2007) extend their 2000 paper by permitting state probabilities to depend on covariates. 
We assume a standard formulation with three components, deterministic, permanent, and transitory, as

$$
y_{i t}=\beta_{t} x_{i t}+\sigma_{t} \eta_{i}+\exp \left(\alpha_{t} x_{i t}\right) \varepsilon_{i t}, \quad t=t_{j}, \ldots, t_{j}+T-1,
$$

with parameters (row-vectors) indexed by calendar time $t$. There are two error components: $\eta_{i}$ is an individual-specific effect, and $\varepsilon_{i t}$ is a strongly stationary idiosyncratic component. Both error components have mean and variance normalized to 0 and 1, respectively, and factor loadings are left unrestricted.

We complete the specification of model (1) as follows.

\subsection{Observed heterogeneity}

The vector $x_{i t}$ of observed individual characteristics comprises experience, squared experience, and five education dummy variables: primary education (I), some high school (II), high school (III), some college (IV), and college graduate (V).

\subsection{Unobserved heterogeneity/permanent component}

We model unobserved heterogeneity $\eta_{i}$ as a strictly exogenous random effect, with zero mean and unitary variance, independent of $x_{i t}$ for all $t$. We assume that $\eta_{i}$ follows a discrete distribution with $K$ support points, $\underline{\eta}_{1}, \ldots, \underline{\eta}_{K}$, with respective probabilities $p_{1}, \ldots, p_{K}$. The c.d.f. of $\eta_{i}$ is thus

$$
F_{\eta}(x)=\sum_{k=1}^{K} p_{k} \mathbf{1}\left\{x \geq \underline{\eta}_{k}\right\},
$$

where $\mathbf{1}\{\cdot\}$ denotes the indicator function, with $\sum_{k=1}^{K} p_{k} \underline{\eta}_{k}=0$ and $\sum_{k=1}^{K} p_{k} \underline{\eta}_{k}^{2}=1$.

The support points are chosen a priori to form a grid on $\mathbb{R}$. In the application, we set $\underline{\eta}_{k}=$ $2 \Phi^{-1}(k /(K+1))$, for $k=1, \ldots, K$. We also set $K$ large enough, and thus the grid fine enough, to approximate a continuous distribution well. The reason why we do not discretize the distribution of $\eta_{i}$ in the frequency domain, like a normal mixture for instance, is that modelling $\eta_{i}$ as a discrete variable will permit to exploit a simple EM algorithm for estimation.

\subsection{Transitory component}

We model $\varepsilon_{i t}$ as a strongly stationary first-order Markov process with zero marginal mean and unitary variance. The only non-stationarity in the transitory component of the log earnings process that is allowed for is the dependence to experience via the variance $\exp \left(2 \alpha_{t} x_{i t}\right)$. In addition, the transitory variance depends on education.

The number of observation periods $(T=3)$ does not allow for a rich structure of state dependence. However, the model can be quite flexible as far as the marginal distribution of $\varepsilon_{i t}$ is concerned because of the very large sample size (more than 30,000 individuals in each subpanel of the French LFS; see Table 2). We thus use a flexible specification for the marginal distribution of $\varepsilon_{i t}$, namely a mixture of $M=3$ normal distributions. The c.d.f. of $\varepsilon_{i t}$ is

$$
F_{\varepsilon_{t}}(x)=\sum_{m=1}^{M} \pi_{m t} \Phi\left(\frac{x-\mu_{m t}}{\omega_{m t}}\right),
$$

with $\sum_{m=1}^{M} \pi_{m t} \mu_{m t}=0$, and $\sum_{m=1}^{M} \pi_{m t} \omega_{m t}^{2}=1$.

In order to map the couples of marginal distributions of $\varepsilon_{i t}$ and $\varepsilon_{i, t+1}$ into the joint distributions of $\left(\varepsilon_{i t}, \varepsilon_{i, t+1}\right)$ we use a copula. Copulas are popular in financial econometrics for modelling 
dependence structures. ${ }^{6}$ Formally, we specify the joint c.d.f. of $\varepsilon_{i t}$ and $\varepsilon_{i, t+1}$ as

$$
F_{\left(\varepsilon_{i t}, \varepsilon_{i, t+1}\right)}(x, y)=C\left(F_{\varepsilon_{t}}(x), F_{\varepsilon_{t+1}}(y)\right),
$$

where $C$ denotes the copula. The copula is the joint c.d.f. of the ranks of variables $\varepsilon_{i t}$ and $\varepsilon_{i, t+1}$ in their respective marginal distributions. One can think of standard matrices of transition probabilities across earnings quintiles or deciles as discrete approximations of the copula density (the second-order partial cross-derivative of the copula).

A copula representation (2) exists for any strongly stationary first-order Markov process, and the copula is unique if the marginal c.d.f.'s $F_{\varepsilon_{t}}$ and $F_{\varepsilon_{t+1}}$ are continuous (Sklar's theorem). The joint density of $\left(\varepsilon_{i t}, \varepsilon_{i, t+1}\right)$ is the product of the two marginal densities and the copula density. Compared to the standard decomposition of a joint density into the product of marginal and conditional densities, the copula representation is thus useful to the extent that it permits independent modelling of marginal distributions and dependence structures.

Copulas are widely used in finance to model correlation patterns, as, for example, default correlation in credit risk models. Here, our use of a copula is motivated by the asymmetry between the large cross-sectional dimension of the French LFS and its small time-series dimension $(T=3)$. A parametric copula allows us to tightly parameterize earnings mobility while keeping marginal distributions flexible. This goal would be more difficult to achieve using an autoregressive moving average (ARMA) model, as the same parameters govern both the marginal distributions and the dependence structure.

Interestingly, economic models do make predictions on the form of copulas. For example, we derive in Appendix A, the particular form of the copula of consecutive earnings for a discretetime version of Burdett and Mortensen (1998) equilibrium search model. The steady-state equilibrium earnings distribution depends on the distribution of firm productivity and search-matching parameters. Yet, the copula only depends on the search-matching parameters, because individual mobility is possible in a steady-state economy only insofar as individuals exchange positions.

After testing several popular copula specifications on the French LFS data, ${ }^{7}$ we selected Plackett's one-parameter copula (see Appendix B for details):

$$
C(u, v ; \tau)=\frac{1}{2} \tau^{-1}\left\{1+\tau(u+v)-\left[(1+\tau(u+v))^{2}-4 \tau(\tau+1) u v\right]^{1 / 2}\right\},
$$

where $(u, v) \in[0,1]^{2}$ are generic ranks. The copula parameter $\tau$ unambiguously indexes mobility from more mobile (low $\tau$ ) to less mobile (high $\tau$ ). In particular, Spearman's $\rho$ is an increasing function of $\tau .{ }^{8}$ We specify $\tau$ as a function of calendar time and observed heterogeneity:

$$
\tau_{t}\left(x_{i t}\right) \equiv \exp \left(\gamma_{t} x_{i t}\right)-1
$$

As an example, Table 1 compares the observed transition probabilities between two consecutive years to the predicted probabilities using Gaussian and Plackett copulas. The Gaussian copula is implicitly assumed in linear autoregressive models with normal margins. We see that it tends to underestimate the dependence in the middle of the distribution, that is, the probabilities of remaining in the second, third, and fourth quintiles. ${ }^{9}$

6. Copulas were initially introduced by Sklar (1959). See Nelsen (1998) and Joe (1997) for references on copulas in statistics and finance.

7. We tried Gaussian, Plackett, Frank, Gumbel, Joe, Clayton, FGM, and Log copulas.

8. Let $X$ and $Y$ be two random variables with c.d.f.'s $F_{X}$ and $F_{Y}$, respectively. Spearman's $\rho$, or rank's correlation, is given by $\rho=\operatorname{Corr}\left(F_{X}(X), F_{Y}(Y)\right)$.

9. In order to compute the transition probabilities in Table 1 we first regress log earnings on experience and experience squared. We then compute earnings ranks using the empirical c.d.f. of log earnings residuals. Finally, we estimate the copula parameters by maximum likelihood, and compute transition probabilities. 
TABLE 1

Fit of 1990-1991 transition probabilities across earnings quintiles

\begin{tabular}{lllllllllllllll}
\hline \multicolumn{4}{c}{ Observed } & \multicolumn{1}{c}{ Gaussian } \\
\hline 0.68 & 0.21 & 0.08 & 0.03 & 0.00 & 0.66 & 0.25 & 0.08 & 0.01 & 0.00 & 0.73 & 0.20 & 0.04 & 0.02 & 0.01 \\
0.20 & 0.50 & 0.22 & 0.06 & 0.02 & 0.25 & 0.37 & 0.26 & 0.11 & 0.01 & 0.20 & 0.52 & 0.21 & 0.05 & 0.02 \\
0.07 & 0.21 & 0.47 & 0.20 & 0.05 & 0.08 & 0.26 & 0.32 & 0.26 & 0.08 & 0.04 & 0.21 & 0.50 & 0.21 & 0.04 \\
0.03 & 0.06 & 0.19 & 0.53 & 0.19 & 0.01 & 0.11 & 0.26 & 0.37 & 0.25 & 0.02 & 0.05 & 0.21 & 0.52 & 0.20 \\
0.02 & 0.02 & 0.04 & 0.18 & 0.74 & 0.00 & 0.01 & 0.08 & 0.25 & 0.66 & 0.01 & 0.02 & 0.04 & 0.20 & 0.73 \\
\hline
\end{tabular}

\subsection{Unemployment}

We also need to model transitions from and into unemployment. This is important for any reasonable description of labour market trajectories in France where unemployment rates are chronically above or around $10 \%$. Let $e_{i t}$ be the binary variable that is equal to 1 if the individual is employed at time $t$ and 0 otherwise. We assume that

$$
\begin{gathered}
e_{i 1}=\mathbf{1}\left\{\delta_{0 t} x_{i 1}+\zeta_{0 t} \eta_{i}+\xi_{i 1}>0\right\}, \\
e_{i t}=\mathbf{1}\left\{\rho_{t} e_{i, t-1}+\delta_{1 t} x_{i t}+\zeta_{1 t} \eta_{i}+\xi_{i t}>0\right\}, \quad t=2, \ldots, T,
\end{gathered}
$$

where $\xi_{i 1}$ and $\xi_{i t}, t=2, \ldots, T$, follow independent standard normal distributions. ${ }^{10}$ All parameters are indexed by calendar time $t$.

\section{IDENTIFICATION}

In this section, we first discuss the identification of the time-dependent variance and covariance/copula parameters. Then, we discuss the non-parametric identification of marginal distributions of persistent and transitory components.

\subsection{Structural change}

Consider the following simplified version of model (1) without covariates:

$$
\begin{gathered}
y_{i t}=\sigma_{t} \eta_{i}+\omega_{t} \varepsilon_{i t}, \quad t=1, \ldots, T, \\
\operatorname{Var} \eta_{i}=\operatorname{Var} \varepsilon_{i t}=1, \quad \operatorname{Cov}\left(\varepsilon_{i t}, \varepsilon_{i, t-1}\right)=\tau_{t},
\end{gathered}
$$

where, to simplify the notation, we use the same symbol for the covariances and the copula parameters, $\tau_{t}$. With $T$ observations per individual, the number of parameters to estimate is $3 T-1$ and the number of non-redundant data covariances, $\operatorname{Cov}\left(y_{i t}, y_{i t^{\prime}}\right)$, is $T(T+1) / 2$. Clearly, the second-order parameters $\sigma_{t}, \omega_{t}$ and $\tau_{t}$ are not identifiable from second-order moments if $T=3$ (six moments for eight parameters). It is only for $T \geq 5$ that the number of moment conditions is greater than the number of parameters. Moreover, having several overlapping subpanels does not help much. For example, with two subsequent three-year panels we have nine moments for 11 parameters.

To ensure identification, we thus have to restrict the way $\sigma_{t}, \omega_{t}$, and $\tau_{t}$ vary with time. Our solution is to assume that structural change is smooth. We make this statement precise by assuming that $\sigma_{t}, \omega_{t}$, and $\tau_{t}$ can be assumed constant within each three-year panel. That is, instead

10. Note that an alternative would have been to non-parametrically model the unemployment probabilities by education and experience cells. However, this approach is difficult to implement when the number of support points for $\eta_{i}$ $(K)$ gets large, because of the usual curse of dimensionality. 
of indexing parameters on calendar time, we index them on the subpanel index $j$ as $\sigma_{j}, \omega_{j}$, and $\tau_{j}$. The cost of making this assumption is that individuals may face different structural parameters in the same year $t$, depending on when they entered the panel $\left(t_{j}\right)$. Alternatively, one could parameterize the dependence of parameters on calendar time using polynomials, for example. However, this would impose more restrictions across panels. In comparison, our preferred solution is simpler to implement and is reminiscent of the idea of using moving averages to smoothen time series.

In practice, some additional smoothing is necessary. Our first attempts at estimating the model with only panel index dependence resulted in rather imprecise estimates, yet displaying clear patterns. Eventually, we chose the following specification:

- Parameters $\beta_{j}, \pi_{m j}, \mu_{m j}, \omega_{m j}$ vary with $j$ without restriction.

- Parameters $\sigma_{j}, \zeta_{0 j}, \rho_{j}, \zeta_{1 j}$ vary with $j$ as cubic polynomials.

- For parameters $\alpha_{j}, \gamma_{j}, \delta_{0 j}, \delta_{1 j}$ : the intercept and the parameters of education dummies vary with $j$ as cubic polynomials, while the parameters of experience and experience squared do not depend on $j$.

\subsection{Non-parametric identification of the stationary model}

Let us now consider the stationary model

$$
y_{i t}=\eta_{i}+\varepsilon_{i t}
$$

with only three observations per individual (say $t=1,2,3$ ). We assume that $\eta_{i}$ is independent of $\left(\varepsilon_{i t}\right)$. Let $F_{X}$ be a generic notation for the c.d.f. of a random variable $X$, with density $f_{X}=F_{X}^{\prime}$.

If $\left(\varepsilon_{i t}\right)$ is independently distributed, then the marginal distributions of $\eta_{i}$ and $\varepsilon_{i t}$ are non-parametrically identified from the joint distribution of $\left(y_{i t}\right)$ (see Kotlarski, 1967). If $\left(\varepsilon_{i t}\right)$ is first-order Markov with $C$ being the copula of $\left(\varepsilon_{i t}, \varepsilon_{i t+1}\right)$, then the following argument shows how to reconstruct $F_{\eta}, F_{\varepsilon}$, and $C$ from the joint distribution of $\left(y_{i 1}, y_{i 2}, y_{i 3}\right)$.

Start by assuming that the distribution of the individual-specific effect $\eta_{i}$ is known. The distribution $F_{\varepsilon}$ can be uniquely obtained by deconvolution, for example, under the assumption that the characteristic function of $\eta_{i}$ is everywhere different from 0 . Then, consider the joint distribution of $\left(y_{i 1}, y_{i 2}\right)$ :

$$
F_{y_{1}, y_{2}}\left(x_{1}, x_{2}\right)=\int f_{\eta}(z) C\left[F_{\varepsilon}\left(x_{1}-z\right), F_{\varepsilon}\left(x_{2}-z\right)\right] d z .
$$

Suppose that the operator mapping $C$ into $F_{y_{1}, y_{2}}$ given $f_{\eta}, F_{\varepsilon}$ is injective, ${ }^{11}$ then one can recover $C$ uniquely given $F_{\eta}$. Lastly, consider for example the distribution of $\left(y_{i 1}, y_{i 3}\right)$ :

$$
F_{y_{1}, y_{3}}\left(x_{1}, x_{3}\right)=\int f_{\eta}(z)\left[\int_{0}^{1} \partial_{2} C\left(F_{\varepsilon}\left(x_{1}-z\right), v\right) \partial_{1} C\left(v, F_{\varepsilon}\left(x_{3}-z\right)\right) d v\right] d z,
$$

where $\partial_{1} C$ and $\partial_{2} C$ denote the partial derivatives of $C$. Making use of the previous derivations of $F_{\varepsilon}$ and $C$ as functions of $f_{\eta}$, this equation defines another inverse problem that has a unique solution if the operator mapping $f_{\eta}$ into $F_{y_{1}, y_{3}}$ is injective.

The practical implementation of this identification algorithm is not trivial. We eventually decided to use a flexible parametric model, with a discrete approximation for the distribution

11. The injectivity of this operator depends on properties of the distributions of $\eta_{i}$ and $\varepsilon_{i t}$. Characterizing the identifying assumptions at this deeper fundamental level is a difficult task that is outside the scope of this paper. 
of $\eta_{i}$, a mixture of three normal distributions for the distribution of $\varepsilon_{i t}$, and a parsimonious specification of the copula $C .^{12}$

\section{THE DATA}

The study is based on data drawn from the 1990-2002 French Labour Force Survey (LFS), conducted by INSEE, the French statistical institute. This survey is a rotating panel, a third of the sampling units (dwellings) being replaced, every year, by an equivalent number of new units. The 1990-2002 data contain 11 subpanels indexed by the date of entry of individuals, from 19901992 to 2000-2002. Each subpanel has about 150,000 individuals aged 15 or more, in 75,000 households, which are thus interviewed three times, in March of three subsequent years, about various aspects of their employment histories. We use LFS data instead of administrative earnings data, as in Alvarez, Browning and Ejrnæs (2002), because the French register data (DADS) do not follow individuals moving to public jobs, self-employment, or non-employment. Moreover, administrative data contain limited information on individual characteristics.

\subsection{Sample construction}

Self-reported usual weekly hours worked are likely to be mismeasured. For instance, we notice that many individuals alternatively report 39 hours worked in one week (the legal working time in the 1990's), and 40 hours in another. To limit the influence of measurement error in hours on our results, we use monthly earnings rather than hourly wages. The employment status is measured at the time of the interview as well as earnings. Monthly earnings are deflated by the retail price index. We drop all earnings observations for students, retirees and self-employed workers. We only keep male employment/earnings trajectories to limit the role of labour supply as a determinant of earnings dispersion. Finally, we trim earnings below the first and above the ninety ninth percentiles.

Geographical mobility, among other reasons, generates a significant amount of attrition. Only $53 \%$ of the individuals of the sample have complete trajectories, $25 \%$ drop out after the second year, and $22 \%$ after the first year. We assume attrition exogenous to the employmentearnings process.

\subsection{Descriptive statistics}

Table 2 shows a few descriptive statistics. All reported quantities are weighted using the LFS weights. The upper part of the table displays these statistics by calendar year, from 1990 to 2000 . We see that the French working population is slightly ageing between 1990 and 2002 and is also becoming more educated. The log earnings variance increases from 0.171 in 1990 to $0 \cdot 186$ in 1996 , and returns to $0 \cdot 178$ in 2000 . The amplitude of the increase is $8.8 \%$. The unemployment rate (in the sample) sharply increases at the beginning of the period, from $9.5 \%$ in 1991 to $14.1 \%$ in 1994, then remains roughly constant between 1994 and 1999, and drops to $11.6 \%$ in 2000 .

The lower part of the table completes the description by showing statistics by date of entry in the panel: from $1990(-1992)$ to $2000(-2002) .{ }^{13}$ We document average earnings growth and relative earnings immobility, as measured by Spearman's $\rho$ (rank's correlation), over one or two

12. Our estimation results will show that when we increase the number of support points for the distribution of $\eta_{i}$, the estimated discrete distribution apparently converges to a continuous limit (see Figure 1).

13. All individuals in the 1990 cross-section are treated as individuals entering the panel in 1990 because, in the estimation, we are not estimating separate parameters for the 1988 and 1989 cohorts, earnings data being measured by interval before 1990. A proper treatment of the cohorts of individuals entering the LFS panel before 1990 would have thus required a more complicated model. 


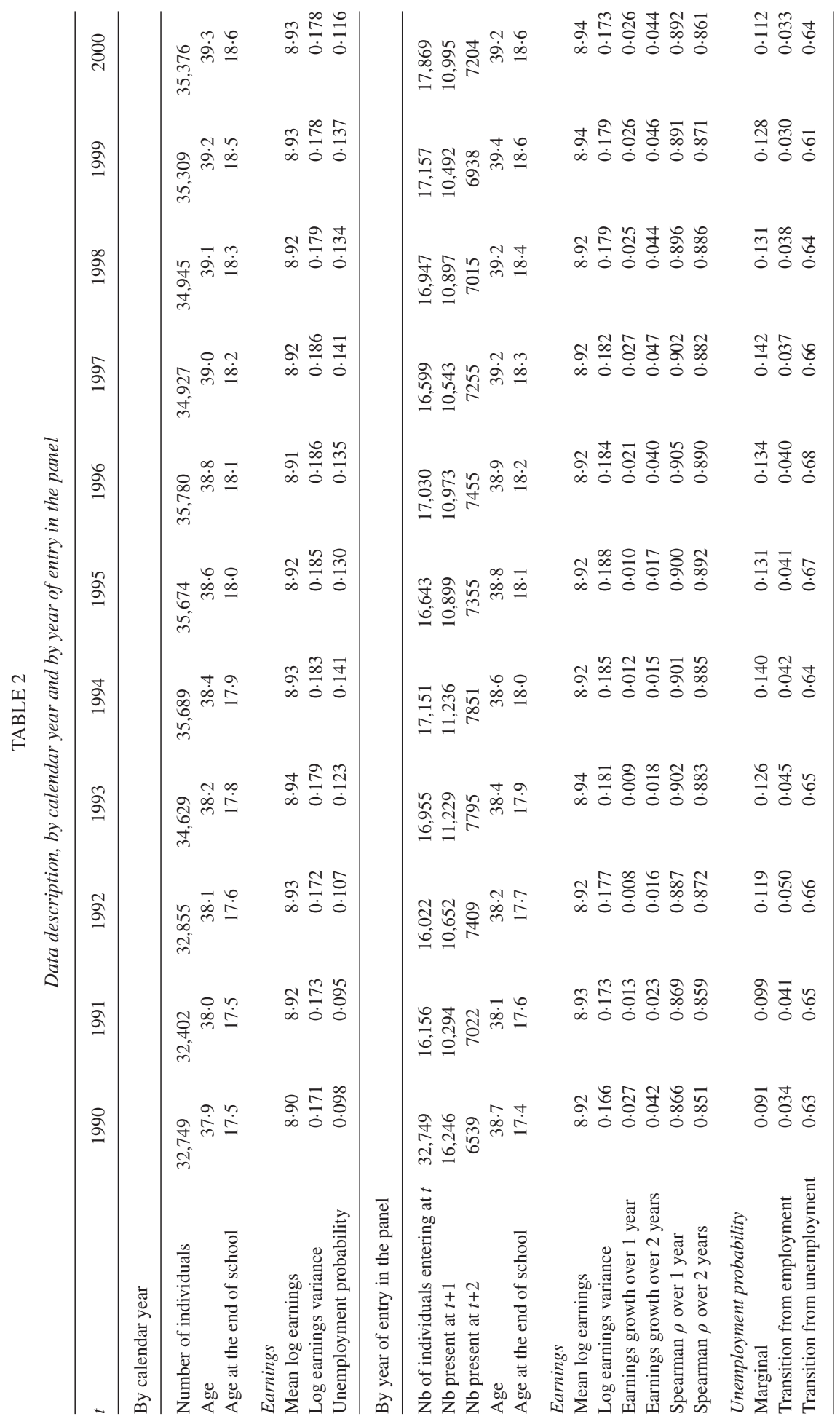




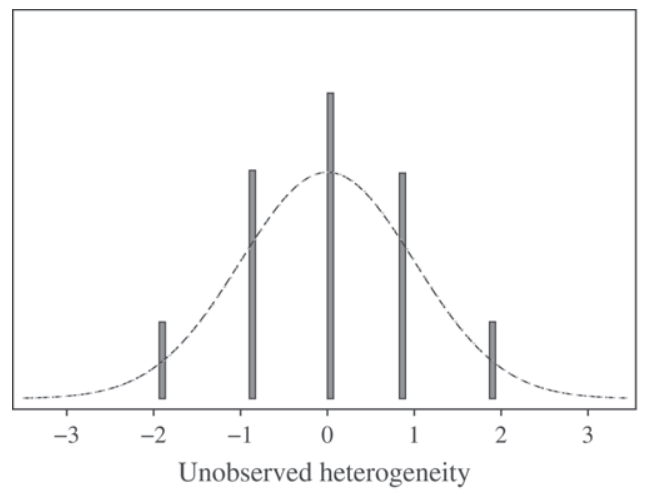

$$
K=5
$$
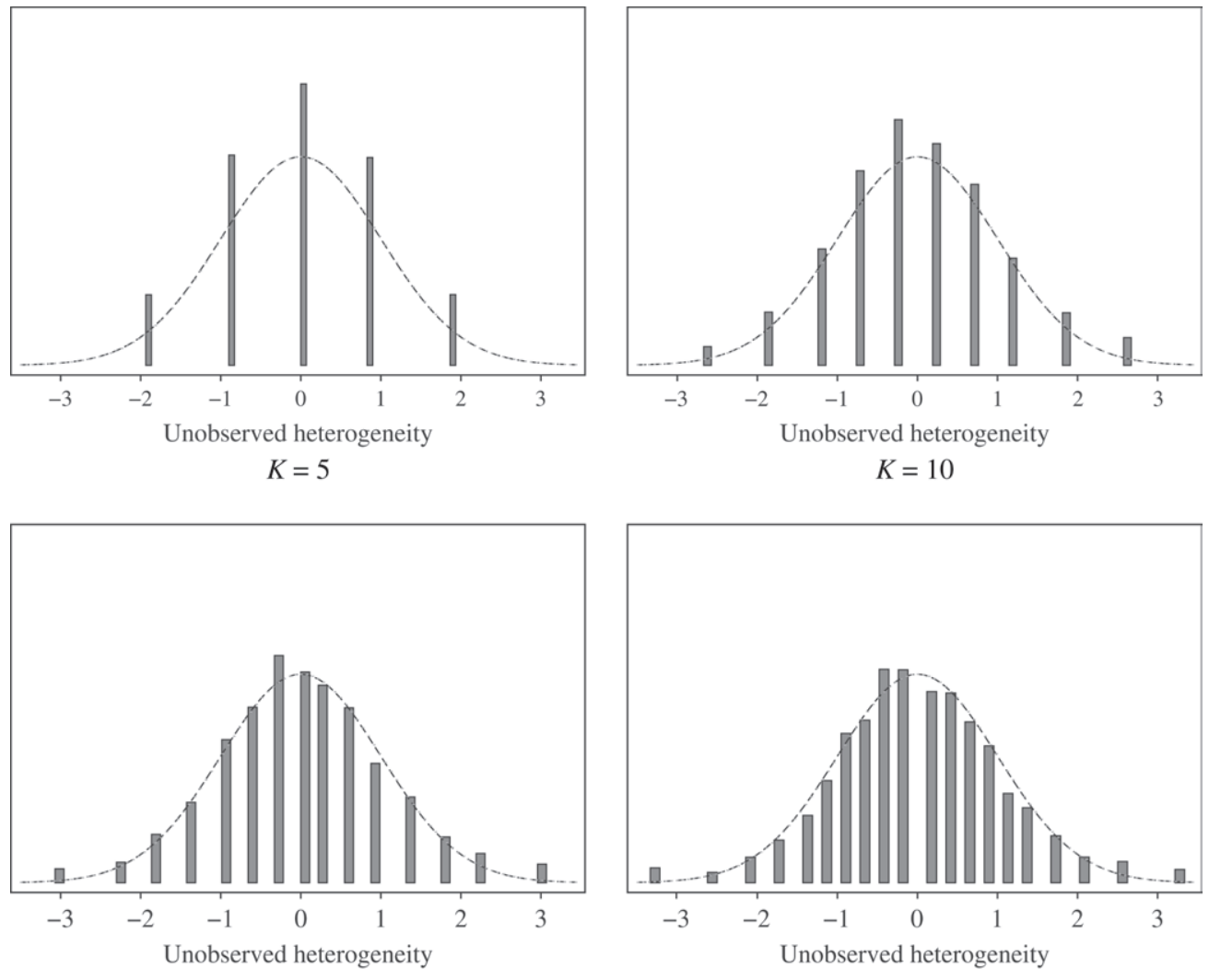

$K=15$

$K=20$

$($ solid line $=$ data dashed line $=$ standard normal density $)$

FIGURE 1

Distribution of unobserved heterogeneity, $\eta_{i}$, for different values of $K$, the number of support points

years. Earnings mobility clearly decreases in the first half of the decade and increases in the second half.

Overall, the first half of the 1990's is thus characterized by a simultaneous increase in earnings inequality, earnings immobility and unemployment risk, and the second half by a symmetrical decrease.

\section{ESTIMATION RESULTS}

The true value of the unobserved heterogeneity component $\eta_{i}$ being equal to $\underline{\eta}_{k}$ with probability $p_{k}$, the likelihood for one individual observation is a discrete mixture. We take advantage of this property in the estimation to develop a sequential variant of the EM algorithm that is detailed in Appendix C. Using arguments similar to Arcidiacono and Jones (2003), this estimation procedure can be shown to deliver a consistent estimator of the model's parameters, asymptotically equivalent to a GMM estimator. This algorithm is very simple to implement but is slow to converge, as usually are EM-type algorithms. It delivers, as a by-product of the estimation, the posterior probabilities of unknown types $\underline{\eta}_{k}$, which can be used to simulate individual trajectories.

In the remainder of this section, we present the parameter estimates that the EM algorithm delivers for all subpanels 1990-1992 to 2000-2002. 
TABLE 3

Parameter estimates for subpanel 1990-1992

\begin{tabular}{|c|c|c|c|c|c|}
\hline & \multicolumn{3}{|c|}{ Log earnings } & \multicolumn{2}{|c|}{ Unemployment } \\
\hline & $\begin{array}{l}\text { Mean } \\
(\beta, \sigma)\end{array}$ & $\begin{array}{l}\text { Volatility } \\
\qquad(\alpha)\end{array}$ & $\begin{array}{l}\text { Mobility } \\
(\gamma)\end{array}$ & $\begin{array}{c}\text { Initial } \\
\left(\delta_{0}, \zeta_{0}\right)\end{array}$ & $\begin{array}{c}\text { Transition } \\
\left(\delta, \rho, \zeta_{1}\right)\end{array}$ \\
\hline Expe & $\begin{array}{c}0.03776 \\
(0.00112)\end{array}$ & $\begin{array}{c}-0.01172 \\
(0.0191)\end{array}$ & $\begin{array}{c}0 \cdot 06154 \\
(0 \cdot 00713)\end{array}$ & $\begin{array}{l}-0.1104 \\
(0 \cdot 00351)\end{array}$ & $\begin{array}{l}-0.05234 \\
(0.00538)\end{array}$ \\
\hline$(100 \times)$ Expe $^{2}$ & $\begin{array}{l}-0.06113 \\
(0.00237)\end{array}$ & $\begin{array}{l}0.07065 \\
(0.0380)\end{array}$ & $\begin{array}{c}-0.04738 \\
(0.0144)\end{array}$ & $\begin{array}{c}0.2154 \\
(0.00751)\end{array}$ & $\begin{array}{c}0.1049 \\
(0.0110)\end{array}$ \\
\hline Educ II & $\begin{array}{c}0.1850 \\
(0.00808)\end{array}$ & $\begin{array}{l}0.1206 \\
(0.187)\end{array}$ & $\begin{array}{c}0.1026 \\
(0.0462)\end{array}$ & $\begin{array}{l}-0.5928 \\
(0.0259)\end{array}$ & $\begin{array}{l}-0.2576 \\
(0.0347)\end{array}$ \\
\hline Educ III & $\begin{array}{c}0.4269 \\
(0.0104)\end{array}$ & $\begin{array}{l}0.7416 \\
(0.194)\end{array}$ & $\begin{array}{c}0.7007 \\
(0.0586)\end{array}$ & $\begin{array}{l}-0.8137 \\
(0.0374)\end{array}$ & $\begin{array}{l}-0.4092 \\
(0.0518)\end{array}$ \\
\hline Educ IV & $\begin{array}{c}0.5869 \\
(0.0137)\end{array}$ & $\begin{array}{l}0.5230 \\
(0.264)\end{array}$ & $\begin{array}{c}0.6368 \\
(0.0766)\end{array}$ & $\begin{array}{l}-1.282 \\
(0.0636)\end{array}$ & $\begin{array}{l}-0.4968 \\
(0.0770)\end{array}$ \\
\hline Educ V & $\begin{array}{c}0.8952 \\
(0.0134)\end{array}$ & $\begin{array}{c}1.086 \\
(0.206)\end{array}$ & $\begin{array}{c}0.9898 \\
(0.0747)\end{array}$ & $\begin{array}{l}-1 \cdot 315 \\
(0.0633)\end{array}$ & $\begin{array}{l}-0.6853 \\
(0.0863)\end{array}$ \\
\hline$\eta_{i}$ & $\begin{array}{c}0.2304 \\
(0.00321)\end{array}$ & - & - & $\begin{array}{l}-0.7775 \\
(0.0137)\end{array}$ & $\begin{array}{l}-0.3334 \\
(0.0167)\end{array}$ \\
\hline$e_{i, t-1}$ & - & - & - & - & $\begin{array}{c}1.744 \\
(0.0384)\end{array}$ \\
\hline Constant & $\begin{array}{c}8 \cdot 173 \\
(0 \cdot 0130)\end{array}$ & $\begin{array}{l}-3.486 \\
(0.266)\end{array}$ & $\begin{array}{c}1.107 \\
(0.0869)\end{array}$ & $\begin{array}{l}-0.1165 \\
(0.0354)\end{array}$ & $\begin{array}{l}-1.115 \\
(0.0612)\end{array}$ \\
\hline
\end{tabular}

Notes: educ, education; expe, experience.

\subsection{Distribution of unobserved heterogeneity}

Figure 1 shows the distribution of the individual effect $\eta_{i}$ for different choices of support. We draw the density of the standard normal distribution for comparison. There is clear evidence of a "convergence" of the distribution of $\eta_{i}$ to a continuous density when $K$ increases. Moreover, this density resembles a standard normal density. This finding is consistent with what Horowitz and Markatou (1996) found for the U.S., using a model with an individual-specific effect and i.i.d. transitory shocks. It is also consistent with the idea that the unobserved heterogeneity component aggregates many missing individual characteristics.

\subsection{Effects of covariates}

Table 3 displays parameter estimates for subpanel 1990-1992, all other subpanels yielding similar estimates. Asymptotic S.E.'s are given in parentheses. ${ }^{14}$

The mean log earnings is concave in experience, with a maximum at 31 years. The copula parameter is monotonically increasing in experience, and so relative mobility decreases with experience. The relation between unemployment risk and experience is U-shaped, with a minimum at 25 years of experience. This is true for the initial probability of being unemployed as well as for the transition probabilities into unemployment. Lastly, the log earnings volatility (i.e. the variance of the transitory component) is U-shaped in experience: it initially decreases with experience, and starts to increase after eight years.

Education has an increasing effect on the mean log earnings and the log earnings volatility, and a decreasing effect on mobility and unemployment risk. The unobserved heterogeneity component $\eta_{i}$ has the same effects as education. Lastly, the strong positive effect of $e_{i t-1}$ on $e_{i t}$ shows that the employment status is highly persistent, even after accounting for unobserved heterogeneity.

14. We report the asymptotic S.E.'s of the last EM step before numerical convergence, that is, taking the prior probability of each heterogeneity type as given. These are thus likely to be understated. 


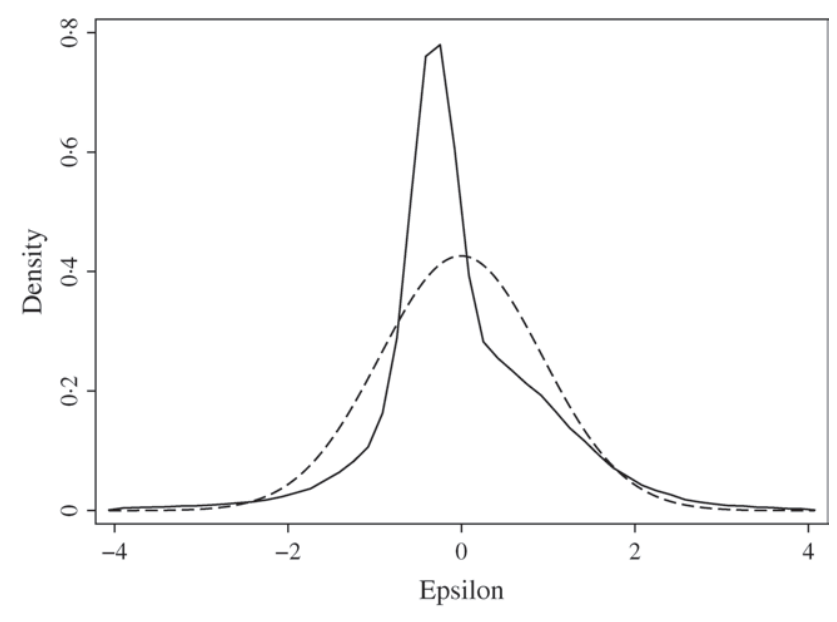

$($ solid line $=$ data dashed $=$ standard normal density $)$

FIGURE 2

Density of $\varepsilon_{i t}$ for subpanel 1990-1992

On Figure 2 we draw the density of $\varepsilon_{i t}$. We observe that the distribution is highly nonnormal, displaying a very peaked mode and some skewness to the left. This visual impression is confirmed by the skewness and kurtosis values equal to 0.26 and $7 \cdot 5$, respectively. The nonnormality of transitory shocks $\varepsilon_{i t}$ contrasts with the near-normality of the permanent component $\eta_{i}$. Using a much longer panel, Geweke and Keane (2000) also find strong evidence of leptokurtic transitory shocks (but they constrain individual-specific effects to be Gaussian).

\subsection{Changes across subpanels}

The left panel in Figure 3 shows the evolution of the variance of the deterministic component of $\log$ earnings, that is, $\operatorname{Var}\left(\beta_{j} x_{i t}\right)$. It increases from $0 \cdot 070$ in $1990-1992$ to 0.081 in $1995-1997$ (a 16\% increase), and returns to its initial level in 2000-2002.

In Table 4 we report the results of an Oaxaca decomposition, taking 1990-1992 as reference. The contribution of age and education to the log earnings variance (row labelled "composition effects" in the Table) increases in France in the 1990's because the average age and education of the labour force increase in this period (see Table 2). Composition effects account for six percentage points (out of 16) of the rise of the log earnings variance between 1990-1992 and 1995-1997. Allowing returns to education to change (in the second row), the variance decreases. This is because returns to education decrease in France in the 1990's (see Figure 4). At the same time, returns to experience increase very steeply during the first half of the 1990's (30\%) and compensate for some of the variance reduction due to lower returns to education. ${ }^{15}$

The central and right panels in Figure 3 display the evolution of two key parameters, that we shall refer to as the permanent and transitory components of the log earnings variance. The first parameter is $\sigma_{j}^{2}$, and is approximately equal to the variance of the effect of unobserved heterogeneity $\eta_{i}$ on log earnings. ${ }^{16}$ The second parameter is the average volatility, namely the

15. The effect of experience on the mean log earnings is quadratic in the model, so the return to experience is linear in experience. The mean return in the sample is reported on the right panel of Figure 4.

16. The variance of $\eta_{i}$ in the sample of employed workers is not exactly equal to 1 because unemployment risk also depends on $x_{i t}$ and $\eta_{i}$, and, therefore, the sample of employed workers, for whom we observe earnings, is endogenously selected. 


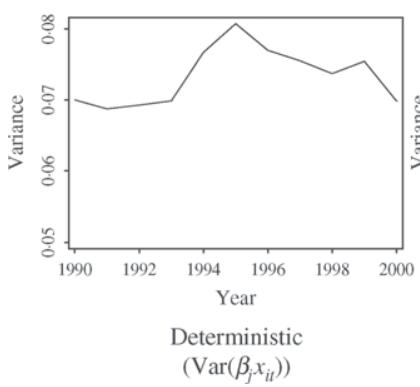

$\left(\operatorname{Var}\left(\beta_{j} x_{i t}\right)\right)$

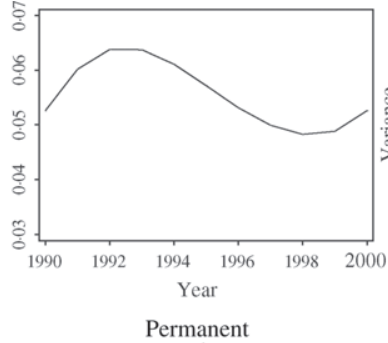

$\left(\sigma_{j}^{2}\right)$

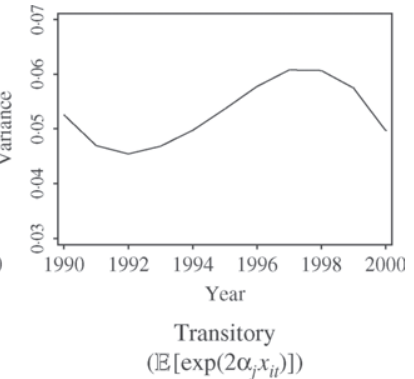

$\left(\mathbb{B}\left[\exp \left(2 \alpha_{j} x_{i t}\right)\right]\right)$

FIGURE 3

Decomposition of the cross-sectional variance of log earnings, subpanels 1990-1992 to 2000-2002

TABLE 4

Oaxaca decomposition of the deterministic component of the variance of log earnings (reference $=1990-1992$ )

\begin{tabular}{lccccc}
\hline & 1990 & 1993 & 1995 & 1997 & 2000 \\
\hline Composition effects & 0.0700 & 0.0704 & 0.0741 & 0.0734 & 0.0742 \\
+ Returns to education & 0.0700 & 0.0700 & 0.0733 & 0.0696 & 0.0666 \\
+ Returns to experience & 0.0700 & 0.0699 & 0.0807 & 0.0755 & 0.0698
\end{tabular}

mean of $\exp \left(2 \alpha_{j} x_{i t}\right)$ (the square of $\left.\exp \left(\alpha_{j} x_{i t}\right)\right)$. Figure 3 shows that the deterministic, permanent and transitory components respectively account for about $40 \%, 30 \%$ and $30 \%$ of the $\log$ earnings variance. Moreover, permanent and transitory variances follow opposite business-cycle dynamics. While the permanent component increased by $20 \%$ at the beginning of the observation period, to reach a peak in 1992-1994, meanwhile, the transitory component decreased by $15 \%$. In the 1993 recession, the effect of the permanent component is reinforced while the transitory variance is reduced. ${ }^{17}$

\section{MODEL FIT}

In this section, we evaluate the capacity of the model to reproduce the main features of the data.

\subsection{Marginal earnings distribution and earnings dynamics in 1990-1992}

Figures 5 and 6 compare actual and predicted distributions of log earnings levels $y_{i t}$ and $\log$ earnings residuals $u_{i t}=y_{i t}-\beta_{j} x_{i t}$ for $1990-1992 .{ }^{18}$ In Figure 5, we separately consider the distribution of levels, $y_{i t}$, the distributions of first and second differences, $y_{i t}-y_{i t-1}$ and $y_{i t}-$ $y_{i t-2}$, and the distribution of three-year averages, $\left(y_{i t}+y_{i t+1}+y_{i t+2}\right) / 3$. Figure 6 repeats this comparison study for residuals. Overall, the fit is good although the model does not fully succeed

17. Baker and Solon (2003) find, using Canadian tax records, that both persistent and transitory variances increased during the recessions of 1982-1983 and 1991-1992. Haider (2001), using U.S. data from the PSID for the period 19671991, finds that the transitory variance increased more during recessions. In comparison, our results could point at a special nature of the 1993 recession in France. However, given the lack of studies covering the period post-1990, it is hard to say how specific to the French context our results are.

18. We predicted these distributions by simulation, using parameters estimated on the subpanel 1990-1992. This requires to simulate transitory shocks from the copula model. We briefly explain how this can be done at the end of Appendix B. 

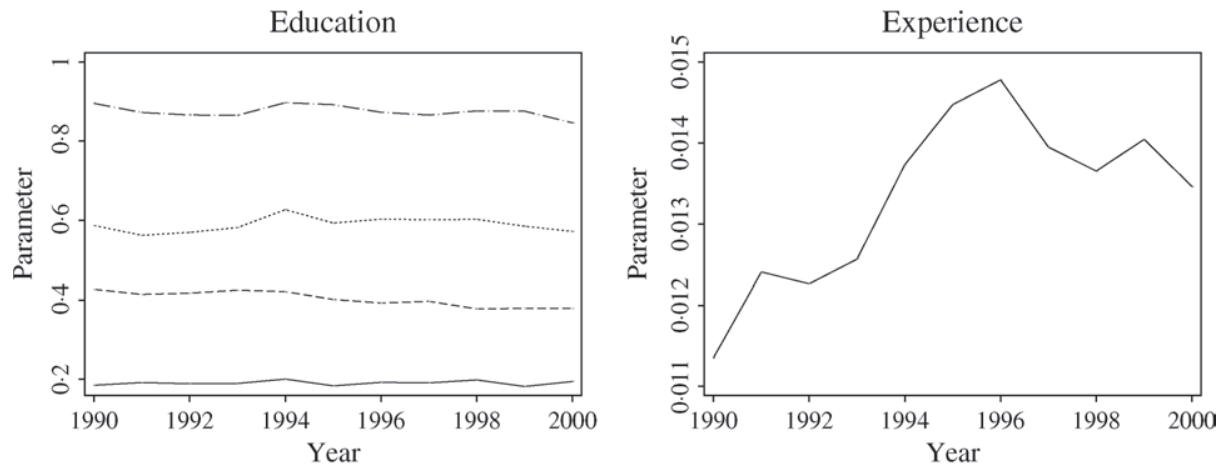

( solid line = level II; dashed = III; dotted = IV;

dashed-dotted $=\mathrm{V}$; Reference level is I)

FIGURE 4

Average returns to education and experience
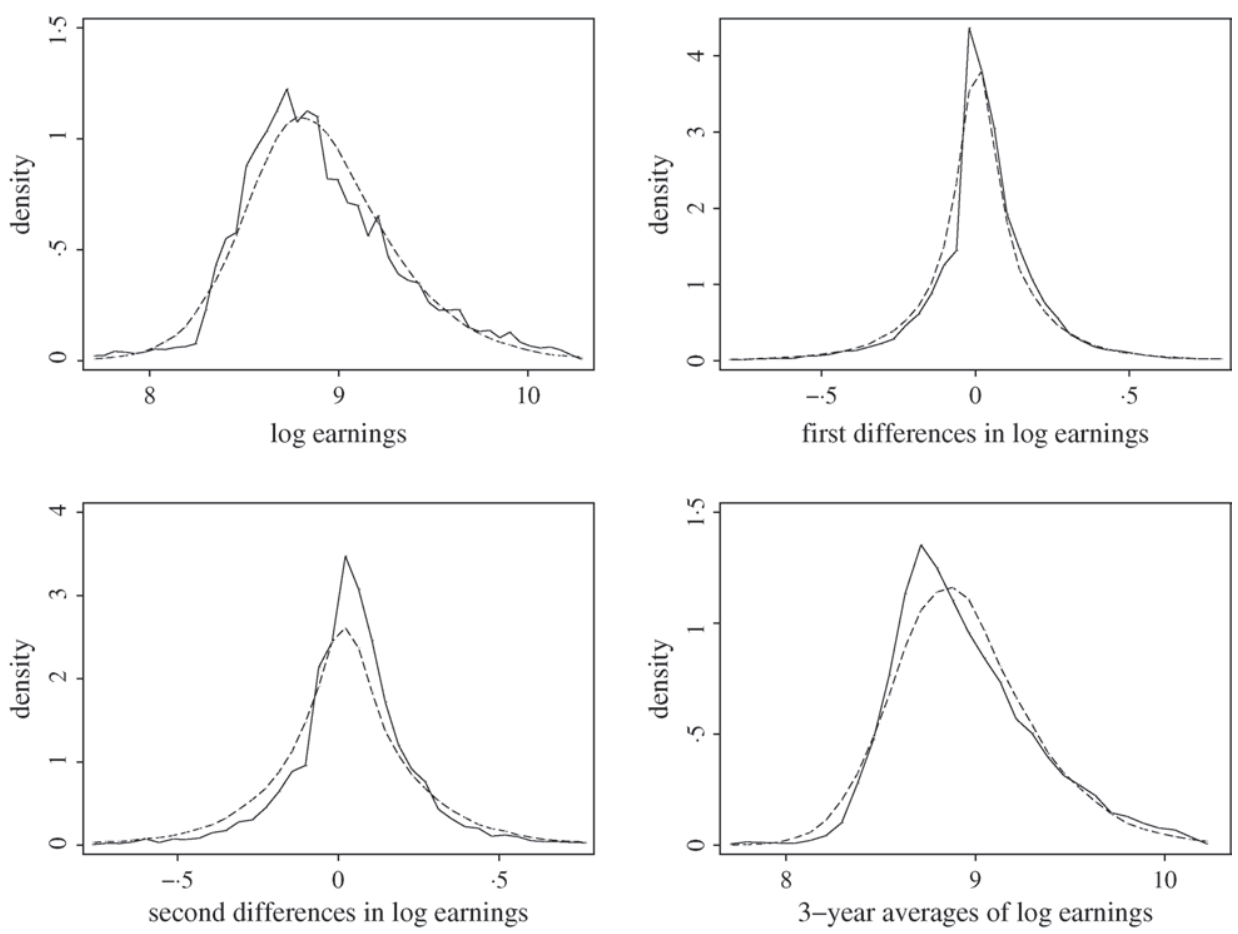

$($ solid line $=$ data , dashed $=$ model's prediction $)$

FIGURE 5

Fit of the marginal distributions of log earnings levels (subpanel 1990-1992)

in capturing the peak of the distribution of second differences. Moreover, comparing the upper left and lower right panels on the two figures shows that the additive structure of the model fails to fit the skewness of log earnings precisely, though the full distribution of log earnings residuals is very well fitted. 

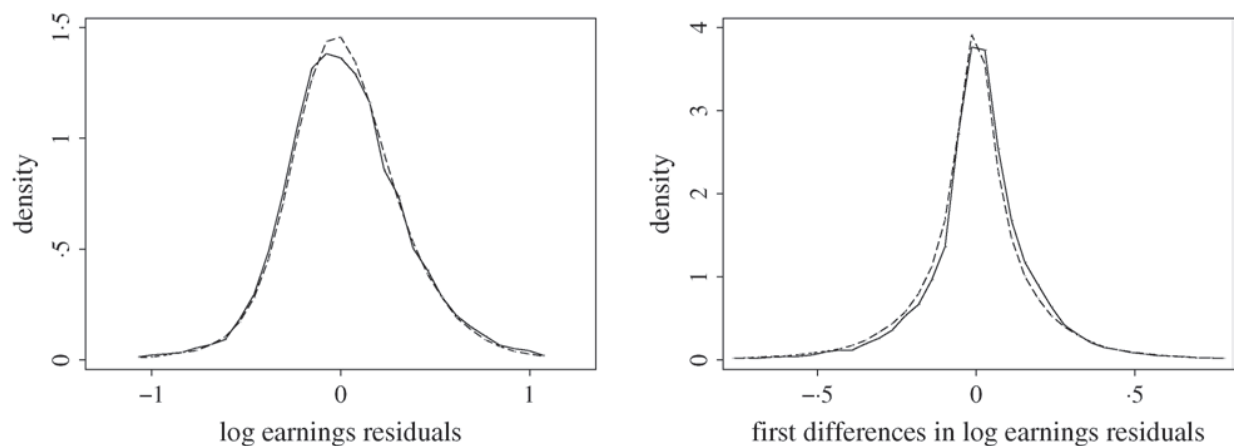

first differences in log earnings residuals
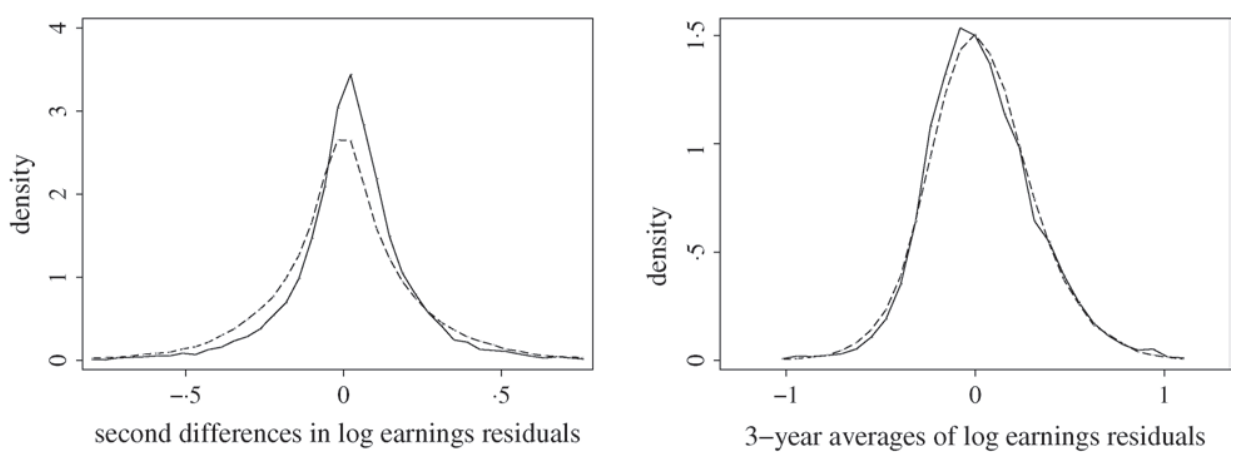

$($ solid line $=$ data; dashed $=$ model's prediction $)$

FIGURE 6

Fit of the marginal distribution of log earnings residuals (subpanel 1990-1992)

TABLE 5

Fit of 1990-1992 transition probabilities across earnings quintiles

\begin{tabular}{|c|c|c|c|c|c|c|c|c|c|c|}
\hline \multirow[b]{2}{*}{ 1990/1991 } & \multicolumn{5}{|c|}{ Actual } & \multicolumn{5}{|c|}{ Predicted } \\
\hline & $0 \cdot 70$ & $0 \cdot 20$ & 0.07 & 0.02 & 0.01 & 0.76 & $0 \cdot 18$ & $0 \cdot 04$ & 0.01 & 0.00 \\
\hline & $0 \cdot 21$ & 0.54 & $0 \cdot 19$ & 0.04 & 0.01 & $0 \cdot 19$ & 0.56 & $0 \cdot 19$ & $0 \cdot 05$ & 0.01 \\
\hline & 0.06 & 0.22 & 0.53 & $0 \cdot 17$ & 0.02 & 0.04 & $0 \cdot 20$ & 0.53 & $0 \cdot 19$ & 0.03 \\
\hline & 0.02 & 0.03 & $0 \cdot 18$ & 0.63 & $0 \cdot 14$ & 0.01 & 0.05 & $0 \cdot 20$ & 0.57 & $0 \cdot 16$ \\
\hline & $0 \cdot 01$ & 0.01 & 0.02 & $0 \cdot 14$ & 0.82 & 0.00 & 0.01 & 0.03 & $0 \cdot 16$ & 0.79 \\
\hline \multirow[t]{5}{*}{$1990 / 1992$} & 0.67 & 0.23 & 0.08 & 0.02 & $0 \cdot 01$ & 0.68 & 0.22 & $0 \cdot 07$ & 0.03 & 0.01 \\
\hline & $0 \cdot 23$ & 0.49 & $0 \cdot 22$ & 0.04 & 0.01 & 0.22 & 0.46 & $0 \cdot 22$ & 0.08 & 0.02 \\
\hline & 0.07 & 0.23 & $0 \cdot 50$ & $0 \cdot 18$ & 0.03 & 0.07 & 0.22 & 0.43 & 0.22 & 0.06 \\
\hline & 0.02 & 0.04 & $0 \cdot 19$ & 0.59 & $0 \cdot 16$ & 0.02 & 0.08 & $0 \cdot 23$ & 0.47 & $0 \cdot 20$ \\
\hline & $0 \cdot 01$ & 0.01 & 0.02 & $0 \cdot 16$ & $0 \cdot 80$ & 0.01 & 0.02 & $0 \cdot 05$ & $0 \cdot 20$ & 0.72 \\
\hline
\end{tabular}

\subsection{Transition probabilities in 1990-1992}

Next, we consider the transition probabilities across earnings quintiles between $t$ and $t+1$, and between $t$ and $t+2$. Actual and predicted probability matrices are displayed in Table 5 . The fit is there also quite good, despite a certain tendency to overestimate mobility in the upper part of the distribution. 

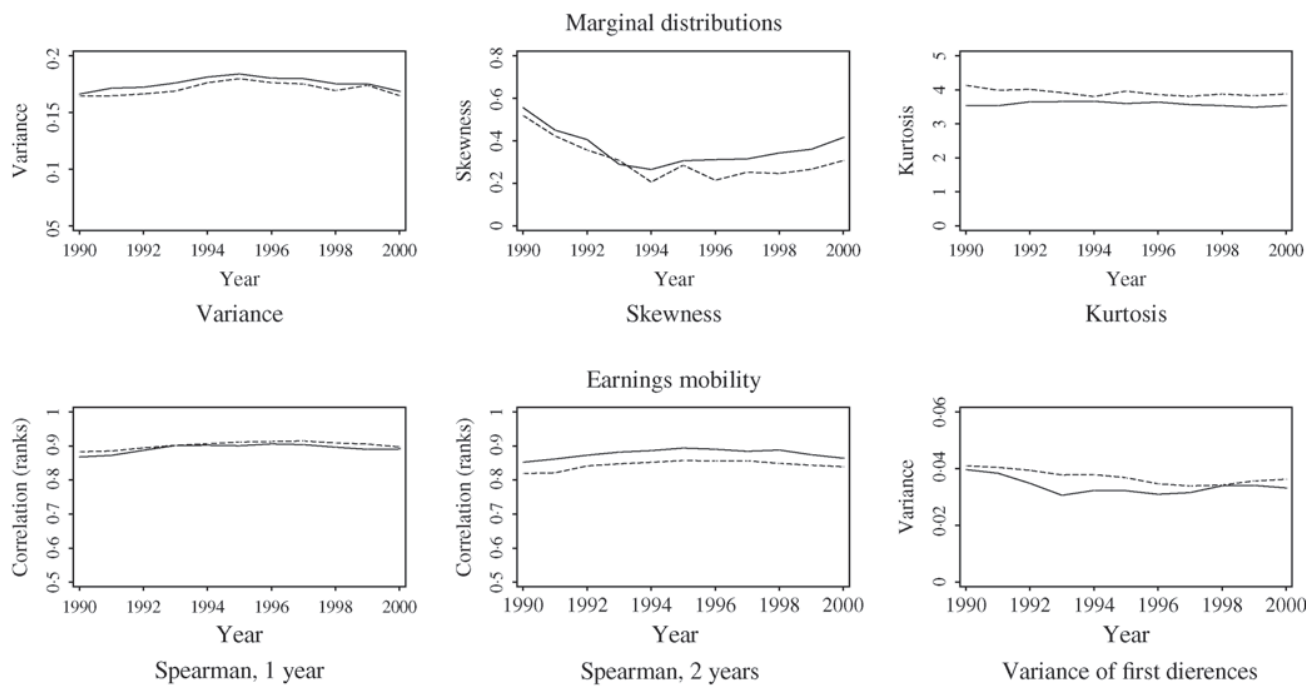

Spearman, 2 years

Variance of first dierences
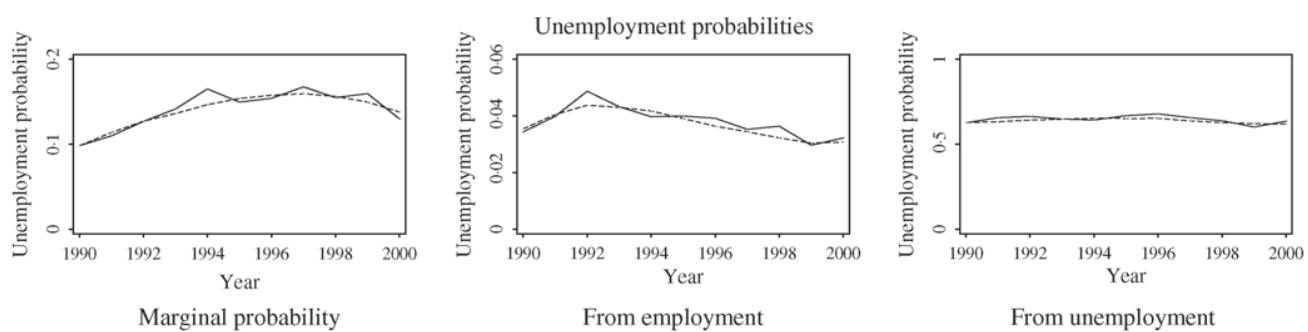

From employment

From unemployment

( solid line $=$ data , dashed $=$ model's prediction $)$

FIGURE 7

Model fit, subpanels 1990-1992 to 2000-2002

\subsection{Evolution, 1990-2000}

Finally, we look at the capacity of the model to reproduce the observed changes in the log earnings distribution, earnings dynamics, and unemployment risk across subpanels, from 1990-1992 to 2000-2002. The top panels of Figure 7 show how the model fits the variance, the skewness, and the kurtosis of log earnings. The middle panels compare Spearman's $\rho$ for actual and simulated log earnings dynamics over one and two years, and the variance of first-differences of log earnings levels. The lower panels plot unemployment probabilities in the first year, and transition probabilities from employment and from unemployment. Again, the overall fit is quite satisfactory, although the central graph shows that the model underpredicts Spearman's $\rho$ two years apart. It is likely that the model predicts too much mobility because of the first-order Markov assumption. It will be important to keep in mind this caveat, due to the very short time length of the French LFS, when interpreting longer-run inequality results in the next section.

\section{LONGER-RUN INEQUALITY}

With a fully parametric model in hand, we can now simulate individual earnings trajectories. Specifically, we assign to every individual in the survey the parameters of the subpanel he belongs to. We then draw a value for the unobserved heterogeneity component $\eta_{i}$ conditional on 
observations, using the posterior distribution of latent variables that the EM algorithm delivers. Next, given $\eta_{i}$ and given the first three employment/earnings observations at $t, t+1, t+2$ we simulate employment/earnings trajectories after $t+2$ until retirement at age 65 . We simulate transitory earnings dynamics using the parametric copula as explained at the end of Appendix B. Lastly, we impute a replacement income to unemployed individuals equal to $60 \%$ of the last earnings. ${ }^{19}$ For each individual who is unemployed in the first year, we draw his "last earnings" from the equilibrium (marginal) earnings distribution.

For a given $H$, we then compute annuitized present values of finite sequences of $H$ future income as

$$
Y_{i t H}^{P}=\frac{Y_{i t}+\beta Y_{i, t+1}+\cdots+\beta^{H_{i t}-1} Y_{i, t+H_{i t}-1}}{1+\beta+\cdots+\beta^{H_{i t}-1}},
$$

where $Y_{i \tau}$ denotes year- $\tau$ income (earnings or unemployment replacement income), $H_{i t}=$ $\min \left\{H, 65-\mathrm{Age}_{i t}\right\}$ is the minimum of $H$ and the remaining time before retirement, and $\beta=0.95$. Computing annuities is important in order to compare the present values of income sequences of different lengths. ${ }^{20}$ When the horizon $H$ is less than the subpanel length, $Y_{i t H}^{P}$ is a sample average.

Our approach extends the classical way of measuring permanent income to short panels by simulating income trajectories beyond the observation period. Contrary to most microsimulation exercises we predict unobserved heterogeneity conditional on observed earnings/employment sequences, and this requires a fully parametric model. However, as the short length of the French LFS forces us to restrict transitory dynamics to be first-order Markov, we expect simulations to be less accurate for higher horizons because of possible specification errors. To allow for richer individual dynamics, longer panels are required, together with a methodology that allows for structural change within the panel time frame.

Table 6 displays the variances of $\log \mathrm{PVs}, y_{i t H}^{P}=\ln Y_{i t H}^{P}$, together with other inequality indices (Gini index and 90/10 percentile ratio), for horizons $H=1,5,10, \infty$ years. In the remainder of this section, we comment on these statistics, displaying them in graphical form to make interpretation easier.

\subsection{The contribution of unemployment to income inequality}

We start by studying the impact of unemployment risk on income inequality. In Figure 8, we compare the variance of $y_{i t H}^{P}$ computed in two samples: the sample of workers employed in period $t$ "employees") and the whole sample of both employed and unemployed workers in period $t$ ("whole sample").

We expect workers employed in year $t$ to face unemployment risk at future dates as all other workers. But, as unemployment has long-lasting consequences, unemployed workers should have lower income present values. In addition, unobserved heterogeneity determines unemployment risk. Hence, the sample of employees in a given year is a selected sample as far as unobservable (permanent) characteristics are concerned. These two effects together explain why there is more current and longer-run income inequality in the whole sample than in the sample of employees.

In cross-section $(H=1)$, we find that the variance of employees' log earnings is one third less than the log income variance in the whole sample. When the horizon increases, the inequality differential between both samples is reduced but never completely disappears (about $15 \%$ for

19. The average replacement ratio in France over the period is $60 \%$, see Martin (1996). Note that we neglect several important features, such as heterogeneity in the replacement ratio, non-stationary UI schemes and specific disutility of unemployment.

20. In the rest of the paper, present values are always annuitized and we keep using the same shorthand PV. 
TABLE 6

Longer-run inequality for various horizons, 1990-2000 (replacement ratio $=60 \%$, discount rate $=5 \%$ )

\begin{tabular}{|c|c|c|c|c|c|c|c|c|}
\hline \multirow[t]{2}{*}{ Year } & \multicolumn{4}{|c|}{ Whole sample } & \multicolumn{4}{|c|}{ Employees only } \\
\hline & 1-year & 5 -year & 10-year & Lifetime & 1-year & 5-year & 10-year & Lifetime \\
\hline \multicolumn{9}{|c|}{ Variance of log } \\
\hline 1990 & $0 \cdot 2449$ & $0 \cdot 2012$ & 0.1858 & 0.1753 & $0 \cdot 1708$ & $0 \cdot 1594$ & 0.1539 & $0 \cdot 1512$ \\
\hline 1991 & 0.2435 & 0.2036 & $0 \cdot 1869$ & $0 \cdot 1765$ & $0 \cdot 1728$ & $0 \cdot 1626$ & $0 \cdot 1569$ & $0 \cdot 1544$ \\
\hline 1992 & $0 \cdot 2494$ & $0 \cdot 2064$ & $0 \cdot 1902$ & $0 \cdot 1791$ & $0 \cdot 1718$ & $0 \cdot 1622$ & 0.1576 & $0 \cdot 1552$ \\
\hline 1993 & $0 \cdot 2621$ & $0 \cdot 2170$ & $0 \cdot 1991$ & $0 \cdot 1864$ & $0 \cdot 1792$ & $0 \cdot 1717$ & $0 \cdot 1670$ & $0 \cdot 1647$ \\
\hline 1994 & $0 \cdot 2758$ & 0.2259 & $0 \cdot 2072$ & 0.1943 & $0 \cdot 1830$ & $0 \cdot 1745$ & $0 \cdot 1705$ & $0 \cdot 1694$ \\
\hline 1995 & $0 \cdot 2720$ & $0 \cdot 2276$ & $0 \cdot 2085$ & 0.1958 & 0.1849 & 0.1778 & $0 \cdot 1717$ & $0 \cdot 1694$ \\
\hline 1996 & $0 \cdot 2729$ & 0.2258 & $0 \cdot 2054$ & $0 \cdot 1913$ & 0.1856 & 0.1758 & $0 \cdot 1703$ & $0 \cdot 1677$ \\
\hline 1997 & $0 \cdot 2748$ & 0.2249 & $0 \cdot 2048$ & $0 \cdot 1907$ & $0 \cdot 1858$ & $0 \cdot 1750$ & $0 \cdot 1690$ & $0 \cdot 1661$ \\
\hline 1998 & $0 \cdot 2647$ & $0 \cdot 2180$ & $0 \cdot 1995$ & $0 \cdot 1877$ & $0 \cdot 1785$ & $0 \cdot 1702$ & $0 \cdot 1642$ & $0 \cdot 1622$ \\
\hline 1999 & 0.2659 & $0 \cdot 2151$ & 0.1954 & $0 \cdot 1830$ & $0 \cdot 1778$ & 0.1663 & $0 \cdot 1600$ & 0.1579 \\
\hline 2000 & $0 \cdot 2511$ & $0 \cdot 2060$ & 0.1886 & $0 \cdot 1784$ & $0 \cdot 1778$ & $0 \cdot 1655$ & 0.1596 & $0 \cdot 1575$ \\
\hline \multicolumn{9}{|l|}{ Gini } \\
\hline 1990 & 0.2689 & $0 \cdot 2490$ & 0.2416 & 0.2367 & $0 \cdot 2409$ & $0 \cdot 2317$ & $0 \cdot 2275$ & $0 \cdot 2255$ \\
\hline 1991 & 0.2675 & 0.2499 & 0.2421 & 0.2374 & $0 \cdot 2410$ & 0.2332 & 0.2290 & $0 \cdot 2273$ \\
\hline 1992 & 0.2686 & $0 \cdot 2501$ & $0 \cdot 2429$ & 0.2380 & 0.2390 & 0.2317 & $0 \cdot 2285$ & 0.2270 \\
\hline 1993 & 0.2740 & 0.2558 & $0 \cdot 2485$ & 0.2433 & $0 \cdot 2419$ & 0.2369 & 0.2345 & 0.2333 \\
\hline 1994 & 0.2792 & 0.2598 & 0.2526 & 0.2476 & 0.2435 & 0.2387 & 0.2368 & 0.2365 \\
\hline 1995 & 0.2774 & $0 \cdot 2603$ & 0.2522 & $0 \cdot 2470$ & $0 \cdot 2440$ & $0 \cdot 2400$ & 0.2365 & $0 \cdot 2352$ \\
\hline 1996 & 0.2796 & 0.2599 & $0 \cdot 2514$ & 0.2452 & $0 \cdot 2453$ & 0.2389 & 0.2358 & $0 \cdot 2341$ \\
\hline 1997 & $0 \cdot 2803$ & 0.2594 & $0 \cdot 2506$ & 0.2444 & 0.2453 & 0.2388 & 0.2350 & 0.2332 \\
\hline 1998 & 0.2755 & 0.2557 & $0 \cdot 2472$ & $0 \cdot 2421$ & $0 \cdot 2415$ & 0.2356 & $0 \cdot 2317$ & 0.2306 \\
\hline 1999 & 0.2757 & 0.2538 & $0 \cdot 2448$ & 0.2389 & 0.2410 & 0.2335 & $0 \cdot 2292$ & $0 \cdot 2274$ \\
\hline 2000 & $0 \cdot 2708$ & $0 \cdot 2506$ & 0.2425 & 0.2373 & $0 \cdot 2424$ & 0.2339 & $0 \cdot 2298$ & 0.2277 \\
\hline \multicolumn{9}{|c|}{ Percentile ratio, $P 90 / P 10$} \\
\hline 1990 & $3 \cdot 323$ & 2.954 & $2 \cdot 836$ & 2.782 & $2 \cdot 826$ & 2.714 & 2.638 & 2.633 \\
\hline 1991 & $3 \cdot 253$ & 2.963 & $2 \cdot 857$ & 2.789 & $2 \cdot 802$ & 2.714 & 2.664 & $2 \cdot 652$ \\
\hline 1992 & 3.459 & 2.994 & 2.893 & $2 \cdot 843$ & 2.799 & 2.708 & 2.684 & $2 \cdot 687$ \\
\hline 1993 & 3.694 & $3 \cdot 104$ & 2.950 & 2.879 & $2 \cdot 831$ & 2.784 & 2.738 & 2.728 \\
\hline 1994 & $3 \cdot 905$ & $3 \cdot 173$ & $3 \cdot 012$ & 2.950 & $2 \cdot 916$ & 2.797 & 2.782 & 2.779 \\
\hline 1995 & $3 \cdot 820$ & $3 \cdot 183$ & $3 \cdot 041$ & 2.966 & $2 \cdot 884$ & $2 \cdot 828$ & 2.784 & 2.792 \\
\hline 1996 & $3 \cdot 833$ & $3 \cdot 203$ & 3.022 & $2 \cdot 940$ & $2 \cdot 834$ & $2 \cdot 787$ & $2 \cdot 749$ & $2 \cdot 770$ \\
\hline 1997 & $3 \cdot 894$ & $3 \cdot 180$ & 3.019 & 2.955 & 2.788 & $2 \cdot 804$ & 2.767 & 2.773 \\
\hline 1998 & $3 \cdot 845$ & $3 \cdot 116$ & 2.954 & 2.902 & 2.729 & 2.766 & 2.722 & 2.736 \\
\hline 1999 & 3.839 & 3.084 & 2.920 & $2 \cdot 872$ & 2.729 & 2.766 & 2.722 & 2.736 \\
\hline 2000 & 3.482 & 3.022 & 2.880 & 2.858 & $2 \cdot 855$ & 2.745 & 2.689 & 2.710 \\
\hline
\end{tabular}

lifetime earnings). The memory of the initial inequality does not vanish as the horizon increases, despite the stationarity assumed in simulating trajectories.

The figure also displays the evolution of the log PV variance differential of employees vs. all workers (employed and unemployed). It decreases at the beginning of the period, from 0.70 in 1990 to 0.66 in 1994. Thus, income inequality increases more than earnings inequality following the 1993 recession, mirroring the increase in the unemployment rate. This business-cycle effect vanishes in the long run.

\subsection{The structure of longer-run income inequality}

In this section we decompose the log PV variance into four components. The first one is the deterministic contribution of differences in education and experience across individuals. It is calculated as the between-group variance of $y_{i t H}^{P}$ across education and experience cells. The second one, called permanent, captures unobserved heterogeneity differences $\left(\eta_{i}\right)$. We compute it as the within-group variance-by education and experience-of $y_{i t H}^{P}$ simulated with transitory shocks 


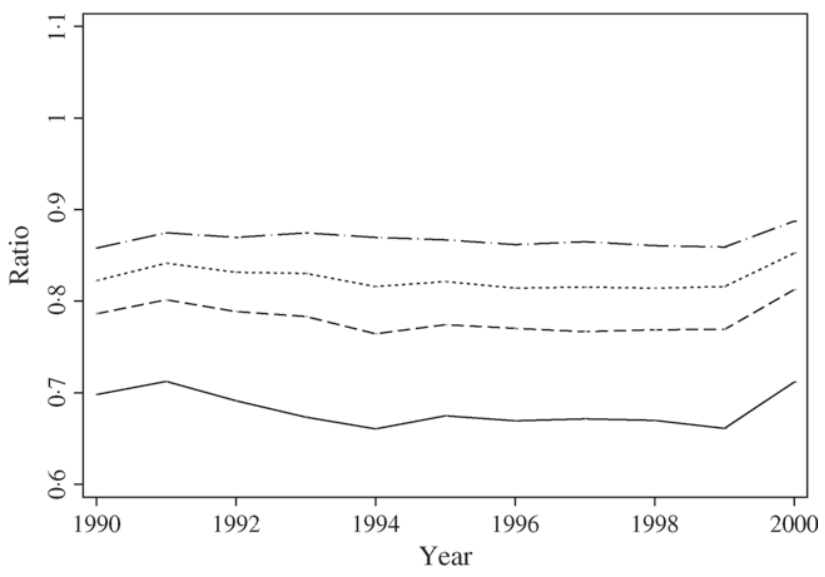

( solid line $=1$ year; dashed $=5$ years; dotted $=10$ years; dashed-dotted $=$ lifetime $)$

FIGURE 8

Variance of log PVs of employees' earnings as a proportion of the variance of log PVs of workers' income in the whole sample (replacement ratio $=60 \%$ and discount rate $=5 \%$ )

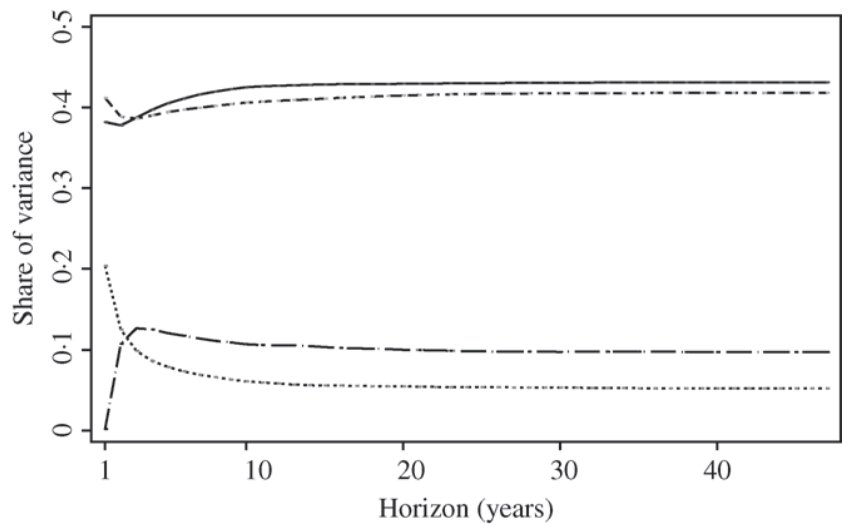

$($ solid line $=$ deterministic component; dashed $=$ permanent; dotted $=$ transitory; dashed-dotted $=$ persistent $)$

FIGURE 9

Decomposition of log PV variance as a function of the horizon in 1990 (replacement ratio of 60\% and discount rate of $5 \%$ )

set to 0 in order to cancel any source of persistence other than $\eta_{i}$. The third and fourth components measure the contribution of transitory shocks. Because transitory shocks are persistent, we decompose their contribution as follows. A first transitory component (simply called transitory) is calculated as the within-group variance-by education, experience, and unobserved heterogeneity-of $y_{i t H}^{P}$ simulated with i.i.d. transitory shocks, that is, setting the copula parameter to 0. A persistent component is lastly computed as the residual variance.

Figure 9 shows the results for the year 1990. The deterministic and permanent components both explain approximately $40 \%$ of the total variance of $y_{i t H}^{P}$ for all $H$. Transitory shocks contribute as follows. Initially, in cross-section, the transitory component accounts for $20 \%$ of the variance. When the horizon increases its share rapidly decreases to $8 \%$ after five years and $5 \%$ 
after 20 years. In contrast, the share of the persistent component rises to $13 \%$ after 3 years, and then moderately decreases to $10 \%$. The total contribution of transitory shocks to lifetime income inequality slightly decreases with the horizon and accounts for $15-20 \%$ of the total variance of lifetime income PVs. ${ }^{21}$

Hence, the structure of longer-run earnings inequality remains very much constant after five years. This is an interesting result, which shows that the use of five-year sequences goes a long way towards capturing the distribution of lifetime PVs. Note, however, that the level of inequality decreases steadily with the time horizon. Table 6 shows that the variance of log PVs computed over five years is $82 \%$ of its cross-section value (0.2012 vs. 0.2449$)$, while it decreases to $76 \%$ over 10 years $(0 \cdot 1858)$ and $72 \%$ for lifetime PVs $(0 \cdot 1753)$.

\subsection{Evolution, 1990-2000}

In this section we document the evolution of longer-run income inequality over the 1990's. Panel (a) of Figure 10 shows the evolution of the variance of $y_{i t H}^{P}$ in the sample of employees and the whole sample, separately.

Longer-run inequality follows a similar hump-shaped pattern as cross-sectional earnings inequality. However, the amplitude is significantly larger. For example, the variance of log PV of lifetime income $(H=\infty)$ in the whole population of both employed and unemployed workers grows from 175 in 1990 to $0 \cdot 196$ in 1995 - a $12 \%$ increase-and then returns to 0.178 in 2000. For one-year income, the increase between 1990 and 1995 is $11 \%$.

Panel (b) of Figure 10 displays the evolution of the variance of $y_{i t H}^{P}$ in proportion to the variance of $y_{i t 1}^{P}$. As more mobility makes individuals exchange position more frequently, this ratio is an index of immobility, and its evolution measures the changes in the equalizing force of mobility over the decade (see Shorrocks, 1978; Fields, 2005). Two remarks are in order. First, according to this index, there is much less mobility in the sample of employees than in the whole sample. In the whole sample, the ratio of five-year and lifetime income inequality to the cross-sectional variance ranges around $82 \%$ and $72 \%$, respectively. In the sample of employees, the immobility index is always close to $90 \%$. The differences in the levels reflect the greater homogeneity of the employees' sample. The fact that the horizon matters less for the subsample of employees is due to unemployment being a transitory state.

Second, and importantly, the equalizing force of mobility remains remarkably constant over the decade. Indeed, in the whole sample the ratio of lifetime to cross-sectional income inequality varies between $72 \%$ (in 1991) and 69\% (in 1999). This near constancy is all the more noticeable as all inequality indices follow a marked hump-shaped pattern. ${ }^{22}$ These results imply that crosssectional income inequality is already quite informative of the evolution of longer-run income inequality, provided that unemployed workers are included in the base sample with lower imputed replacement income.

\section{MODEL COMPARISON EXERCISES}

In this section, we perform two model checks: we test the sensitivity of the previous results to unemployment risk, and we measure the consequences of non-Gaussianity and non-linearity in the process of transitory shocks. ${ }^{23}$

21. Geweke and Keane (2000, table 11), using the PSID, regress the PVs of lifetime earnings on observables and unobserved individual effects. They find that observable account for 20-35\% of the variance of PVs, unobserved individual effects account for $35-45 \%$, and between $25 \%$ and $35 \%$ of the variance is left unexplained.

22. The Gini index gives a similar picture. However, being less sensitive to the lower tail of the earnings distribution, the effect of unemployment is less pronounced.

23. We also evaluated the effect of neglecting unobserved heterogeneity on longer-run inequality. We found that both the level and the persistence of inequality are then strongly understated. 


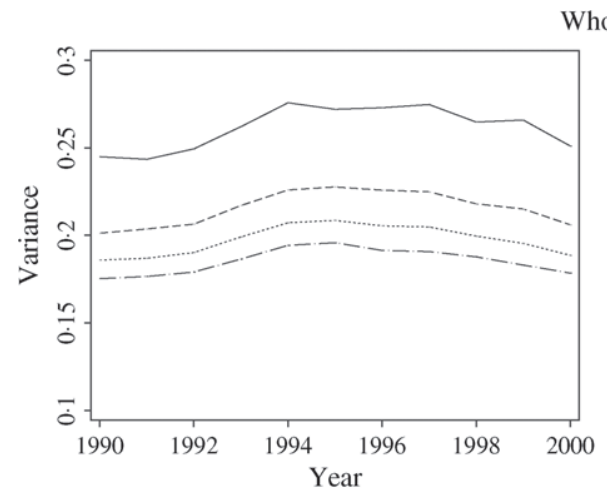

Whole sample

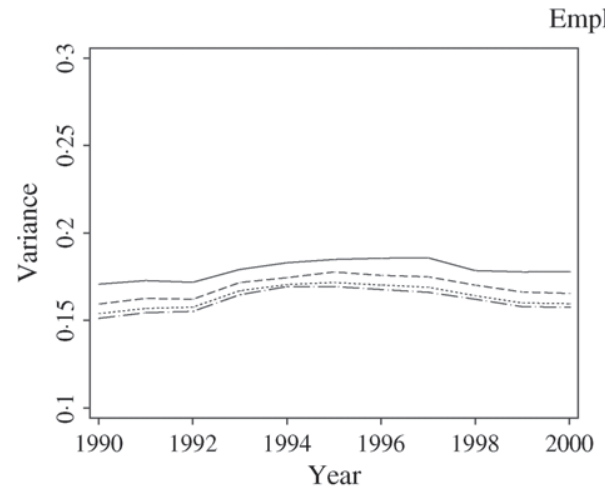

( solid line $=1$ year; dashed $=5$ years; dotted $=10$ years; dashed-dotted $=$ lifetime $)$

(a) Log PV variance

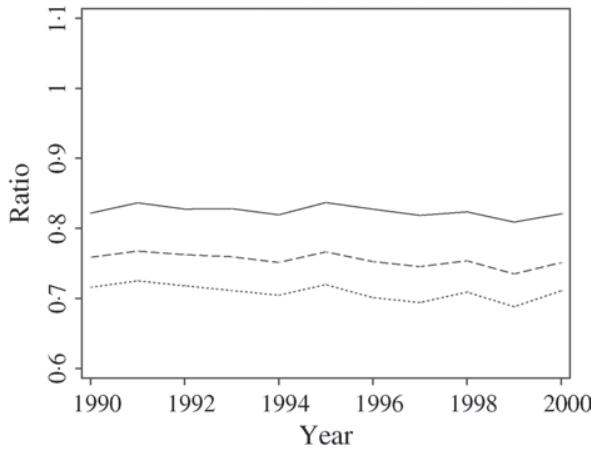

Employees only

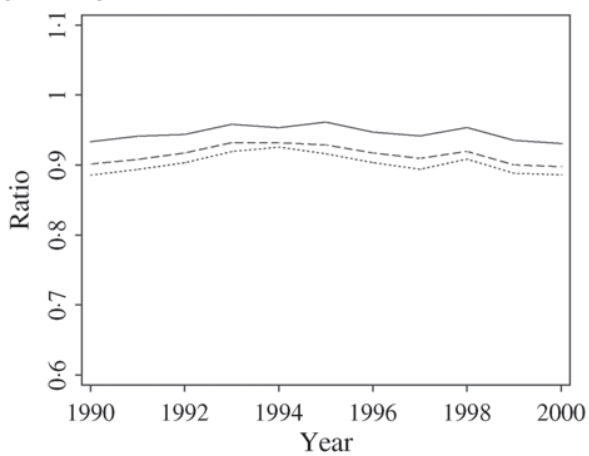

( solid line $=5$ years; dashed $=10$ years; dotted $=$ lifetime)

(b) Immobility index

FIGURE 10

Longer-run income inequality (replacement ratio $=60 \%$ and discount rate $=5 \%$ )

\subsection{Varying unemployment risk}

We first study the sensitivity to unemployment insurance by varying the replacement ratio of UI benefits between $40 \%$ and $80 \%$. Given the UI legislation in France, these percentages can be seen as conservative lower and upper bounds for unemployment compensation. Figure 11 shows that lowering the replacement ratio from $80 \%$ to $40 \%$ has important effects on longer-run income inequality. Inequality rises by about $25 \%$ (lifetime) or $60 \%$ (one year). The depressing effect of the 1993-1995 recession is also more pronounced when the replacement ratio is lower, as unemployment risk increases in 1993. Finally, the equalizing force of mobility is stronger, the immobility index decreasing from $75 \%$ to $60 \%$ when the replacement ratio decreases from $80 \%$ to $40 \%$. This is because employment spells last on average much longer than unemployment spells, making unemployment shocks to income intense but transitory. ${ }^{24}$

Second, we study the consequence of suppressing unemployment risk altogether. The results of this exercise are displayed in Figure 12. Lifetime earnings inequality increases by $11 \%$ from 1990 to 1995 , a close match to the $12 \%$ increase generated by the actual parameters. So, cancelling unemployment risk has small effects on the evolution of the equalizing force of

24. Note that in the case where the replacement ratio is $40 \%$ the immobility index varies slightly more over the business cycle, with a low in 1994 when the unemployment rate is highest. 

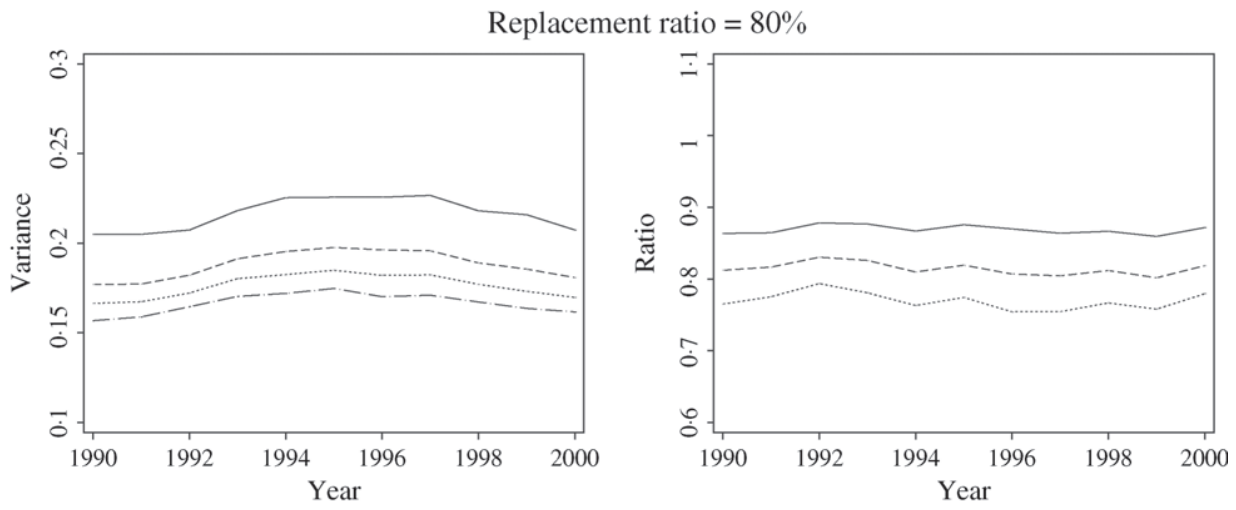

Replacement ratio $=40 \%$

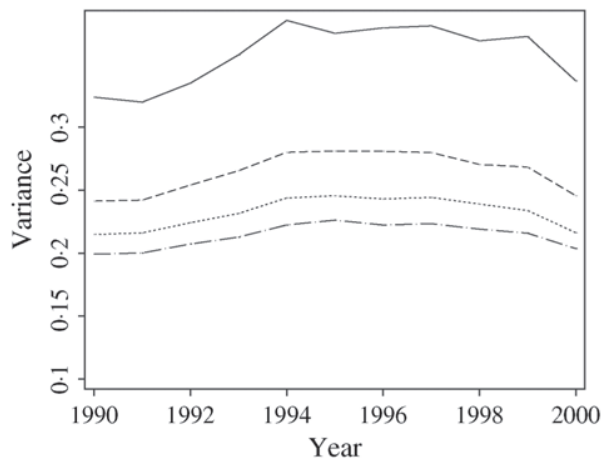

(solid line $=1$ year; dashed $=5$ years; dotted $=10$ years; dashed-dotted $=$ lifetime)

(a) Log PV variance

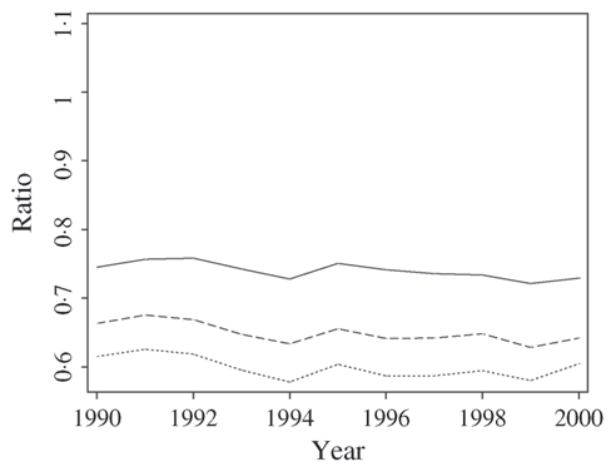

( solid line $=5$ years; dashed $=10$ years; dotted $=$ lifetime)

(b) Immobility index

FIGURE 11

Longer-run income inequality for replacement ratios of $40 \%$ and $80 \%$ (whole sample)

mobility. However, we see that the level of inequality is now noticeably smaller (e.g. $0 \cdot 155$ vs. 0.175 in 1990), and that lifetime earnings inequality is more persistent (index of immobility of about $80 \%$ instead of $72 \%$ ).

\subsection{Gaussian transitory shocks and copula}

Most earnings models assume linear dynamics and Gaussian innovations. In our model, the transitory process $\left(\varepsilon_{i t}\right)$ is $\mathrm{AR}(1)$ if margins and copula are all Gaussian. We already established that the distribution of the permanent component $\eta_{i}$ is approximately normal, but that neither the margins of $\left(\varepsilon_{i t}\right)$, nor the copula, are Gaussian. We now study the effect on longer-run inequality of estimating and simulating a fully Gaussian model. ${ }^{25}$

Table 7 shows the parameter estimates. Compared with Table 3, we see that the Gaussian model yields a very different decomposition of log earnings into deterministic, permanent, and

25. With Gaussian margins, the parameter of the Gaussian copula is also the autoregressive parameter of the AR(1) model. We model it as $\tau_{j}\left(x_{i t}\right)=\exp \left(\gamma_{j} x_{i t}\right)-1$. 


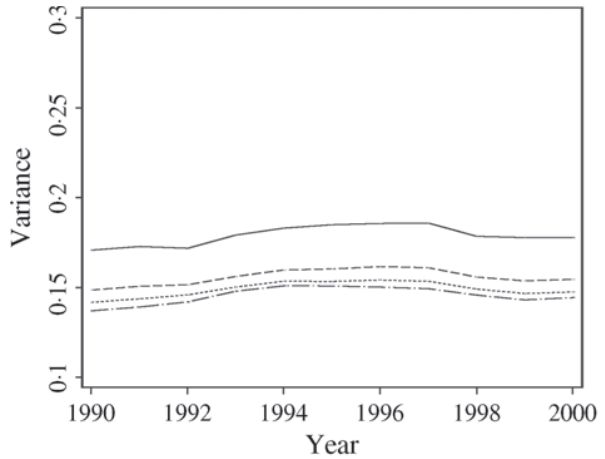

( solid line $=1$ year; dashed $=5$ years; dotted $=10$ years; dashed-dotted $=$ lifetime)

(a) Log PV variance

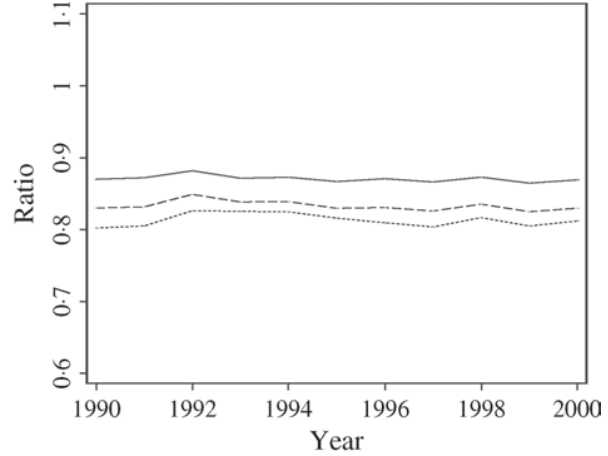

(solid line $=5$ years; dashed $=10$ years; dotted $=$ lifetime)

(b) Immobility index

FIGURE 12

Longer-run income inequality with no unemployment risk (whole sample, replacement ratio $=60 \%$ and discount rate $=5 \%$ )

TABLE 7

Parameter estimates for subpanel 1990-1992, model with Gaussian margins and Gaussian copula

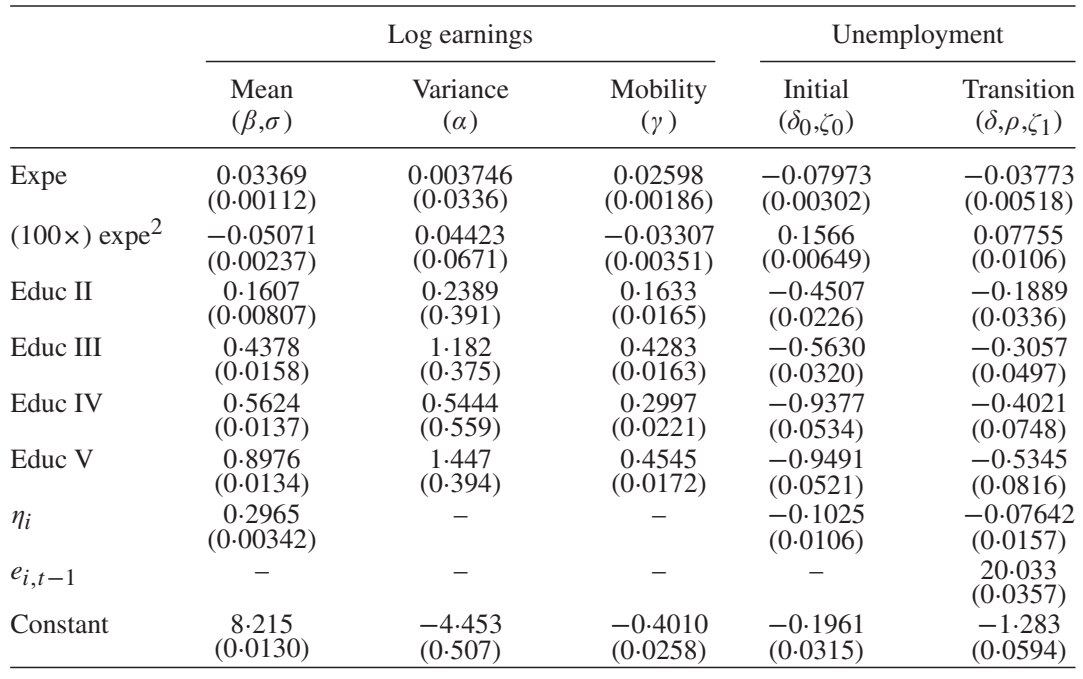

transitory components. Indeed, the variance of the permanent component is $\sigma_{j}^{2}=0 \cdot 2965^{2}=$ 0.088 , compared to $0.2304^{2}=0.053$, that is two thirds more. In the Gaussian model, the unobserved heterogeneity component thus accounts for $50 \%$ of the variance of log earnings, compared to $30 \%$ in the non-Gaussian model. As a consequence, transitory shocks have a smaller variance and are much less persistent. Moreover, the Gaussian model predicts more state dependence in employment (2.03 vs. 1.74 for the autoregressive coefficient in unemployment), but less dependence on unobserved heterogeneity (compare the seventh row in the two tables). We checked that the Gaussian copula, rather than the Gaussian margins, is mostly responsible for the observed differences. Hence, the choice of the parametric copula used to describe dynamic tail dependence does have important consequences on the estimation of the factor loadings. 


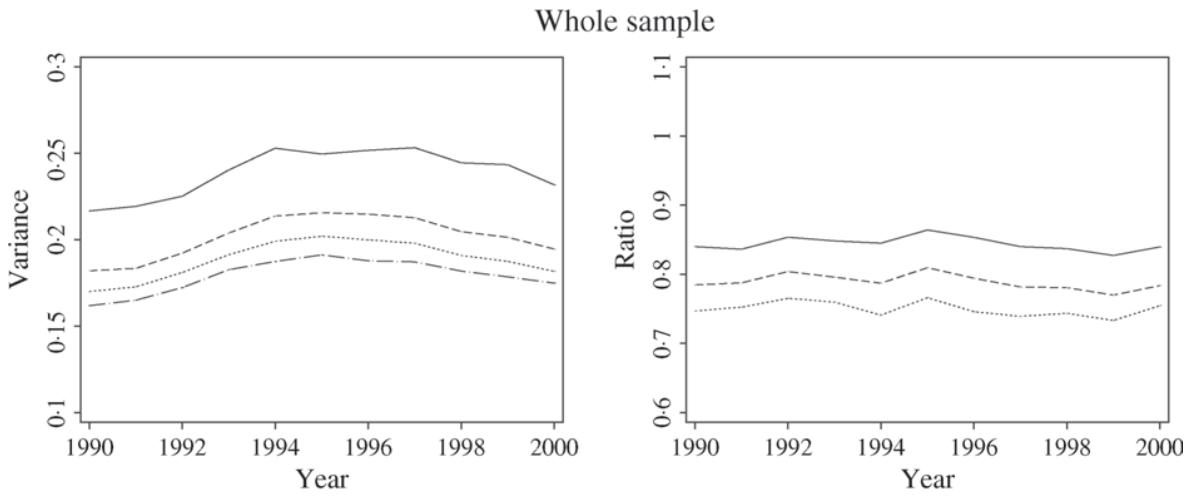

Employees only

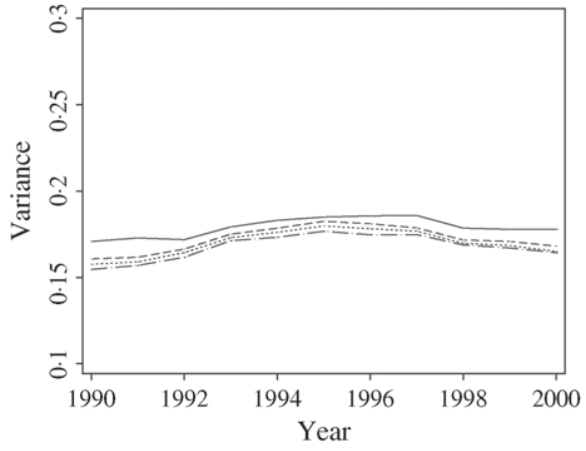

( solid line $=1$ year; dashed $=5$ years; dotted $=10$ years; dashed-dotted $=$ lifetime $)$

(a) Log PV variance

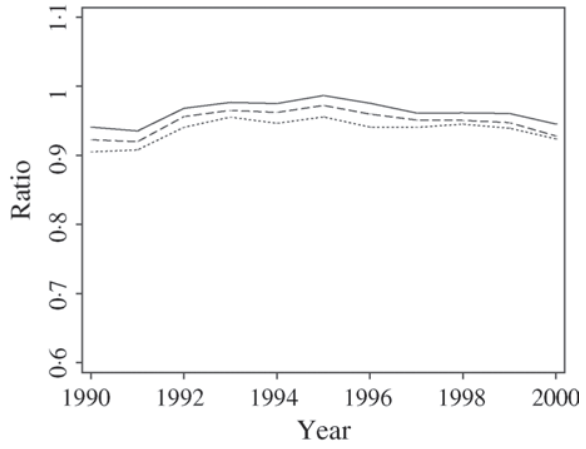

(solid line $=5$ years; dashed $=10$ years; dotted $=$ lifetime)

(b) Immobility index

FIGURE 13

Counterfactual longer-run income inequality under full Gaussianity (replacement ratio $=60 \%$, and discount rate $=5 \%$ )

Figure 13 shows the effect on longer-run inequality. On panel (a), we see that the Gaussian $\mathrm{AR}(1)$ model predicts about $12 \%$ less inequality in cross-section. This is due to the fact that unobserved heterogeneity determines unemployment less than in the non-Gaussian model. The difference in terms of lifetime inequality is smaller, as the Gaussian model predicts about $7 \%$ less lifetime inequality in the whole sample, and $2 \%$ more in the sample of employees. The Gaussian model predicts an immobility index that is about five percentage points higher in the whole sample. For employees, the ratio is close to $90 \%$ in both simulations. The evolutions of inequality and immobility indices are also nearly identical. It is quite remarkable that two models with such different decompositions of the log earnings variances yield so similar lifetime inequality patterns.

\section{CONCLUSION}

In this paper, we study the evolution of cross-sectional and longer-run measures of inequality in France in the 1990's, a period characterized by significant business-cycle fluctuations. For this purpose, we use the French LFS. In order to fit this type of data, we construct a model that combines a flexible specification of the marginal earnings distributions (adapted to the large 
cross-sectional dimension) with a tight parameterization of the dependence structure (that the small number of recording periods requires).

The model's structure is standard, with an individual effect and stationary transitory shocks, and we allow parameters to change with the date of entry of individuals into the panel. We simulate individual trajectories beyond the observation period by drawing from the conditional distribution given observations. The ratio of the inequality of long-run averages of earnings to the inequality in a cross-section is an aggregate measure of the persistence of inequality. Thus, our approach adapts an empirical methodology that previously required long panels to short panels like labour force surveys.

The representation of log earnings as the convolution of several factors is standard in the literature. The necessity of allowing for structural change (i.e. time-varying factor loadings) is now recognized of utter importance. A few recent papers also point at non-linearities in the process of transitory shocks. Our model has all these characteristics while still being simple and interpretable.

We find that the distribution of the unobserved heterogeneity component is approximately Gaussian and the distribution of transitory shocks is leptokurtic. Relative mobility, as measured by the joint distribution of the ranks of two consecutive transitory shocks (i.e. the copula), is also non-Gaussian, and best approximated by Plackett's copula. Unemployment risk and unemployment insurance are found to be an important source of permanent inequality. Despite significant business-cycle fluctuations in earnings inequality, earnings mobility, and unemployment risk in the 1990's, the measure of the persistence of inequality (the immobility index) is remarkably stable.

Moreover, a model comparison exercise shows that the parametric specification chosen for the copula has important consequences on the estimation of factor loadings. A Gaussian copula attributes to unobserved heterogeneity a greater share of the total log earnings variance. As, at the same time, the unemployment process depends less on unobserved heterogeneity, the Gaussiancopula model yields a very similar picture in terms of longer-run inequality. If, as our discussion of identification suggests, the copula is non-parametrically identified, in the future it will be interesting to push the analysis further and estimate a model with a flexible specification of the marginal distributions of fixed effects and transitory shocks and the copula.

It will be also interesting to test the model on longer panels. The basic structure of the model could be extended for that purpose. With four or five observation periods per individual, it should be possible to identify and estimate a model with second-order Markov transitory dynamics, or with an additional measurement error. Another interesting extension is to allow for an additional individual factor governing the unemployment process specifically. The estimation algorithm performs well and could easily be modified to incorporate these extensions.

\section{APPENDIX A}

\section{A.1. Copulas: an economic model}

The main structure of our model is a single factor model with first-order Markov errors. We model individual transitory dynamics using copulas. In Section 2, we justified this choice by the ability of the copula representation to tightly parameterize the dependence structure while being flexible as far as marginal distributions are concerned. In this section of the appendix, we argue that modelling the law of individual earnings processes using copulas also arises naturally in steady-state equilibrium models.

The prototypical steady-state search model describes an economy where a population of heterogeneous firms post different wages, and where a population of homogeneous workers sequentially search for a job both when they are unemployed and when they are employed. The wage offer distribution is some function $F(w)$ that depends on the distribution of productivity across different occupations and the search friction parameters. One can allow for heterogeneity in worker ability by assuming that the labour market is segmented (see, for example, Van den Berg and Ridder, 1998). 
Search frictions are modelled as follows. Time is discrete. At the end of each period, an employee can be laid off with probability $\delta$ or may draw an alternative earnings offer with probability $\lambda$. This alternative offer is a draw $w^{\prime}$ from the equilibrium distribution $F$. Employees accept alternative offers $w^{\prime}$ strictly greater than the current wage $w$. In steady state, the cross-sectional earnings distribution is related to the wage offer distribution by the one-to-one relationship:

$$
G(w)=\frac{F(w)}{1+\kappa[1-F(w)]} \Leftrightarrow F(w)=\frac{(1+\kappa) G(w)}{1+\kappa G(w)},
$$

where $\kappa=\lambda / \delta .^{26}$

Conditional on being employed at time $t$ and $t+1$ (alternative offers thus accrue with conditional probability $\frac{\lambda}{1-\delta}$ ), individual wage dynamics follows a first-order Markov process such that

$$
\begin{aligned}
\operatorname{Pr}\left\{w_{t+1} \leq w^{\prime} \mid w_{t}=w\right\} & =\left(1-\frac{\lambda}{1-\delta}+\frac{\lambda}{1-\delta} F\left(w^{\prime}\right)\right) \mathbf{1}\left\{w^{\prime} \geq w\right\} \\
& =\frac{1}{1-\delta}\left[1-\frac{\delta+\lambda}{1+\kappa G\left(w^{\prime}\right)}\right] \mathbf{1}\left\{w^{\prime} \geq w\right\}
\end{aligned}
$$

where $1\left\{w^{\prime} \geq w\right\}=1$ if $w^{\prime} \geq w$ and 0 otherwise. Hence

$$
\begin{aligned}
\operatorname{Pr}\left\{w_{t+1} \leq w^{\prime}, w_{t} \leq w\right\} & =\frac{1}{1-\delta}\left[1-\frac{\delta+\lambda}{1+\kappa G\left(w^{\prime}\right)}\right]\left(G(w) \mathbf{1}\left\{w^{\prime} \geq w\right\}+G\left(w^{\prime}\right) \mathbf{1}\left\{w^{\prime}<w\right\}\right) \\
& =\frac{1}{1-\delta}\left[1-\frac{\delta+\lambda}{1+\kappa G\left(w^{\prime}\right)}\right] \min \left(G(w), G\left(w^{\prime}\right)\right)
\end{aligned}
$$

The copula thus follows as

$$
C(u, v)=\frac{1}{1-\delta}\left[1-\frac{\delta+\lambda}{1+\kappa v}\right] \min (u, v) .
$$

Hence, the steady-state search-wage-posting model naturally delivers a simple formula for the copula, which only depends on the friction parameters $\delta$ and $\lambda$ and not on the equilibrium wage distribution $F$. We do not use this specification because it would not fit earnings mobility data well (as wage cuts are impossible). Yet, we want to put forward the interpretation that a steady-state labour market can be characterized, first, by the equilibrium wage distribution $G$ (i.e. the marginal distribution of employees' earnings), and, second, by a description of the way workers exchange positions (via mobility rate parameters embodied in the copula $C$ ).

Now, the economy is clearly not in steady state. Structural parameters like $G, \delta$, and $\lambda$ do fluctuate over time. However, there is some evidence that steady-state flow conditions like (A.1) or the classical equality between the unemployment rate and $\delta /\left(\delta+\lambda_{0}\right)$, where $\lambda_{0}$ is the exit rate from unemployment, are empirically well verified (see Postel-Vinay and Robin, 2006; Jolivet, Postel-Vinay and Robin, 2006). This happens because net annual flows are small in relation to gross flows. Over a limited period of time, macro trends can thus be neglected, and it seems that workers only exchange positions. This is how we justify our assumption that each subpanel $S_{j}$ approximately reflects a steady-state economy with a specific set of parameters.

\section{APPENDIX B}

\section{B.1. The Plackett copula}

Plackett (1965) generalizes the independence condition for contingency tables. He shows that, if $U$ and $V$ are uniform random variables on $[0,1]$, then the following equation:

$$
\frac{P(U \leq u, V \leq v) P(U>u, V>v)}{P(U \leq u, V>v) P(U>u, V \leq v)}=\tau+1 \quad \forall(u, v),
$$

where $\tau>-1$ is a given constant, has one single solution. This solution is a copula, and writes:

$$
C(u, v ; \tau)=\frac{1}{2} \tau^{-1}\left\{1+\tau(u+v)-\left[(1+\tau(u+v))^{2}-4 \tau(\tau+1) u v\right]^{1 / 2}\right\} .
$$

26. See Burdett and Mortensen (1998). $\delta+\lambda[1-F(w)]$ is the exit rate from the stock of employees paid less than $w$, which is proportional to $G(w)$. The inflow is itself proportional to $F(w)$.

(C) 2009 The Review of Economic Studies Limited 
Equation (B.1) shows that $\tau$ is a natural mobility index. More precisely, let us define the following ordering $\precsim c$ on copulas, called the concordance ordering (e.g. Joe, 1997):

$$
C_{1} \precsim c C_{2} \quad \text { iff } \quad C_{1}(u, v) \leq C_{2}(u, v), \quad \forall(u, v) .
$$

$\precsim_{c}$ is the first-order stochastic dominance ordering. It measures relative mobility: the ranks process governed by copula $C_{1}$ will be said more mobile than the ranks process governed by $C_{2}$ if $C_{1} \precsim c C_{2}$. Moreover, the concordance ordering possesses a lower and a upper bound (Fréchet, 1935). The lower bound $C_{L}$ satisfies: $C_{L}(u, v)=\max (u+v-1,0)$. The upper bound $C_{U}$ satisfies $C_{U}(u, v)=\min (u, v)$.

The Plackett copula satisfies the following properties (Joe, 1997):

1. $C\left(\cdot, \cdot ; \tau_{1}\right) \precsim c C\left(\cdot, \cdot ; \tau_{2}\right)$ for all $\tau_{2}>\tau_{1}$.

2. $C(\cdot, \cdot ; \tau) \rightarrow C_{L}$ when $\tau \rightarrow-1$.

3. $C(\cdot, \cdot ; \tau) \rightarrow C_{U}$ when $\tau \rightarrow \infty$.

4. $C(\cdot, \cdot ; \tau) \rightarrow C^{\perp}$ when $\tau \rightarrow 0$, where $C^{\perp}(u, v)=u v$ is the independent copula.

Therefore, the Plackett copula is mobility decreasing with respect to its parameter, and the Plackett family covers the whole range of bivariate dependence, from immobility $\left(C_{U}\right)$ to independence $\left(C^{\perp}\right)$ and perfect mobility $\left(C_{L}\right)$.

Simulation. Let $u$ be earnings ranks at time $t$. For given $u$, we here show how to simulate earnings ranks at $t+1$ (v) from the Plackett copula. Note that for $u \in[0,1]$ given, $\frac{\partial C}{\partial u}(u, v)$ is uniform $(0,1)$. So in order to simulate a $v$ draw a uniform $(0,1)$ variable $w$ and solve for $v$ in $\frac{\partial C}{\partial u}(u, v)=w$. In the case of the Plackett copula, this implicit equation writes as a quadratic polynomial equation with two roots in $[0,1]$. Choose the highest or the lowest root with probability $\frac{1}{2}$.

\section{APPENDIX C}

\section{C.1. Estimation algorithm}

Fix $K$, and a grid $\underline{\eta}_{1}, \ldots, \underline{\eta}_{K}$ for the distribution of the permanent component $\eta_{i}$, and fix $M$ the number of Gaussian components for the marginal distribution of transitory shocks $\varepsilon_{i t}$.

Let $\mathbf{x}_{i}=\left(x_{i 1}, \ldots, x_{i T}\right), \mathbf{y}_{i}=\left(y_{i 1}, \ldots, y_{i T}\right)$, and $\mathbf{e}_{i}=\left(e_{i 1}, \ldots, e_{i T}\right)$ be the observations for individual $i$. Let $j(i) \in$ $\{1, \ldots, J\}$ be the index of the panel sample these observations belongs to $\left(i . e . j(i)=j\right.$ such that $i \in \mathcal{S}_{j}$ ).

The likelihood for one individual observation is the discrete mixture:

$$
\ell_{j}\left(\mathbf{y}_{i}, \mathbf{e}_{i} \mid \mathbf{x}_{i}\right)=\sum_{k=1}^{K} p_{k} \ell_{j}\left(\mathbf{y}_{i}, \mathbf{e}_{i} \mid \mathbf{x}_{i}, k\right), \quad i \in \mathcal{S}_{j},
$$

where

$$
\begin{aligned}
\ell_{j}\left(\mathbf{y}_{i}, \mathbf{e}_{i} \mid \mathbf{x}_{i}, k\right)= & P_{j}^{0}\left(e_{i 1} \mid x_{i 1}, k\right) \times \prod_{t=1}^{T-1} P_{j}\left(e_{i, t+1} \mid e_{i t}, x_{i, t+1}, k\right) \times \prod_{t=1}^{T}\left[\frac{1}{\exp \left(\alpha_{j} x_{i t}\right)} f_{j}\left(\epsilon\left(y_{i t} \mid x_{i t}, k\right) \mid x_{i t}\right)\right]^{e_{i t}} \\
& \times \prod_{t=1}^{T-1} c\left[F_{j}\left(\epsilon\left(y_{i t} \mid x_{i t}, k\right) \mid x_{i t}\right), F_{j}\left(\epsilon\left(y_{i t+1} \mid x_{i t+1}, k\right)\right) ; \exp \left(\gamma_{j} x_{i t}\right)-1\right]^{e_{i t} e_{i t+1}}
\end{aligned}
$$

where $c$ is Plakett's copula density, with parameter $\exp \left(\gamma_{j} x_{i t}\right)-1$, and where

$$
\begin{gathered}
\epsilon\left(y_{i t} \mid x_{i t}, k\right)=\frac{y_{i t}-\beta_{j} x_{i t}-\sigma_{j} \underline{\eta}_{k}}{\exp \left(\alpha_{j} x_{i t}\right)}, \\
P_{j}^{0}\left(e_{i 1} \mid x_{i 1}, k\right)=\Phi\left(\delta_{0 j} x_{i 1}+\zeta_{0 j} \underline{\eta}_{k}\right)^{e_{i 1}} \Phi\left(-\delta_{0 j} x_{i 1}-\zeta_{0 j} \underline{\eta}_{k}\right)^{1-e_{i 1},} \\
P_{j}\left(e_{i, t+1} \mid e_{i t}, x_{i, t+1}, k\right)=\Phi\left(\rho_{j} e_{i t}+\delta_{1 j} x_{i, t+1}+\zeta_{1 j} \underline{\eta}_{k}\right)^{e_{i, t+1}} \Phi\left(-\rho_{j} e_{i t}-\delta_{1 j} x_{i, t+1}-\zeta_{1 j} \underline{\eta}_{k}\right)^{1-e_{i, t+1},}, \\
f_{j}\left(\varepsilon_{i t} \mid x_{i t}\right)=\sum_{m=1}^{M} \pi_{m j} f_{j}\left(\varepsilon_{i t} \mid x_{i t}, m\right)=F_{j}^{\prime}\left(\varepsilon_{i t} \mid x_{i t}\right), \\
f_{j}\left(\varepsilon_{i t} \mid x_{i t}, m\right)=\frac{1}{\omega_{m j}} \varphi\left(\frac{\varepsilon_{i t}-\mu_{m j}}{\omega_{m j}}\right)=F_{j}^{\prime}\left(\varepsilon_{i t} \mid x_{i t}, m\right) .
\end{gathered}
$$

Note that we allow for a specific marginal distribution of transitory shocks $\varepsilon_{i t}$ to each subpanel $j$. 
E-step. For initial values of the parameters $p_{k},\left(\mu_{m j}, \pi_{m j}, \omega_{m j}\right),\left(\delta_{0 j}, \mu_{0 j}\right),\left(\rho_{j}, \delta_{1 j}, \mu_{1 j}\right),\left(\beta_{j}, \sigma_{j}, \alpha_{j}\right)$, and $\gamma_{j}$, for each individual in the samples $\mathcal{S}_{j}, j=1, \ldots, J$, compute the posterior probabilities of the latent types of $\eta_{i}$ and $\varepsilon_{i t}$ :

$$
\begin{aligned}
p_{j}\left(k \mid \mathbf{y}_{i}, \mathbf{e}_{i}, \mathbf{x}_{i}\right) & =\frac{p_{k} \ell_{j}\left(\mathbf{y}_{i}, \mathbf{e}_{i} \mid \mathbf{x}_{i}, k\right)}{\ell_{j}\left(\mathbf{y}_{i}, \mathbf{e}_{i} \mid \mathbf{x}_{i}\right)}, \quad k=1, \ldots, K, \\
\pi_{j}\left(m \mid y_{i t}, x_{i t}, k\right) & =\frac{\pi_{m j} f_{j}\left(\epsilon\left(y_{i t} \mid x_{i t}, k\right) \mid x_{i t}, m\right)}{f_{j}\left(\epsilon\left(y_{i t} \mid x_{i t}, k\right) \mid x_{i t}\right)}, \quad m=1, \ldots, M .
\end{aligned}
$$

M-step. With $p_{j}\left(k \mid \mathbf{y}_{i}, \mathbf{e}_{i}, \mathbf{x}_{i}\right)$ and $\pi_{j}\left(m \mid \varepsilon_{i t}, x_{i t}, k\right)$ set to these values,

- Update $p_{k}$ by maximizing

$$
\sum_{j=1}^{J} \sum_{i \in \mathcal{S}_{j}} \sum_{k=1}^{K} p_{j}\left(k \mid \mathbf{y}_{i}, \mathbf{e}_{i}, \mathbf{x}_{i}\right) \ln p_{k}
$$

with respect to $p_{k}$ and subject to

$$
\sum_{k=1}^{K} p_{k}=1, \quad \sum_{k=1}^{K} p_{k} \underline{\eta}_{k}=0, \quad \sum_{k=1}^{K} p_{k} \underline{\eta}_{k}^{2}=1 .
$$

Then for each subpanel $j$ perform the following steps:

- Maximize

$$
\sum_{i \in \mathcal{S}_{j}} \sum_{m=1}^{M} \sum_{k=1}^{K} p_{j}\left(k \mid \mathbf{y}_{i}, \mathbf{e}_{i}, \mathbf{x}_{i}\right) \sum_{t / e_{i t}=1} \pi_{j}\left(m \mid y_{i t}, x_{i t}, k\right) \ln \pi_{m j},
$$

with respect to $\pi_{m j}$ and s.t.

$$
\sum_{m=1}^{M} \pi_{m j}=1, \quad \sum_{m=1}^{M} \pi_{m j} \mu_{m j}=0, \quad \sum_{m=1}^{M} \pi_{m j} \omega_{m j}^{2}=1 .
$$

- Maximize

$$
\sum_{i \in \mathcal{S}_{j}} \sum_{k=1}^{K} p_{j}\left(k \mid \mathbf{y}_{i}, \mathbf{e}_{i}, \mathbf{x}_{i}\right) \ln P_{j}^{0}\left(e_{i 1} \mid x_{i 1}, k ; \delta_{0 j}, \mu_{0 j}\right),
$$

with respect to $\left(\delta_{0 j}, \mu_{0 j}\right)$, and

$$
\sum_{i \in \mathcal{S}_{j}} \sum_{k=1}^{K} \sum_{t=1}^{T-1} p_{j}\left(k \mid \mathbf{y}_{i}, \mathbf{e}_{i}, \mathbf{x}_{i}\right) \ln P_{j}\left(e_{i, t+1} \mid e_{i t}, x_{i, t+1}, k ; \rho_{j}, \delta_{1 j}, \mu_{1 j}\right),
$$

with respect to $\left(\rho_{j}, \delta_{1 j}, \mu_{1 j}\right)$.

- Minimize

$$
\sum_{i \in \mathcal{S}_{j}} \sum_{k=1}^{K} p_{j}\left(k \mid \mathbf{y}_{i}, \mathbf{e}_{i}, \mathbf{x}_{i}\right)\left(y_{i t}-\beta_{j} x_{i t}-\sigma_{j} \underline{\eta}_{k}\right)^{2},
$$

with respect to $\beta_{j}$ and $\sigma_{j}$. Then, compute residuals $u\left(y_{i t} \mid x_{i t}, k\right)=y_{i t}-\beta_{j} x_{i t}-\sigma_{j} \underline{\eta}_{k}$ and minimize

$$
\sum_{i \in \mathcal{S}_{j}} \sum_{k=1}^{K} p_{j}\left(k \mid \mathbf{y}_{i}, \mathbf{e}_{i}, \mathbf{x}_{i}\right)\left[u\left(y_{i t} \mid x_{i t}, k\right)^{2}-\exp \left(2 \alpha_{j} x_{i t}\right)\right]^{2}
$$

with respect to $\alpha_{j}$.

- Compute standardized residuals $\epsilon\left(y_{i t} \mid x_{i t}, k\right)$ and maximize

$$
\sum_{i \in \mathcal{S}_{j}} \sum_{k=1}^{K} p_{j}\left(k \mid \mathbf{y}_{i}, \mathbf{e}_{i}, \mathbf{x}_{i}\right) \sum_{m=1}^{M} \sum_{t / e_{i t}=1} \pi_{j}\left(m \mid y_{i t}, x_{i t}, k\right) \ln \left[\frac{1}{\omega_{m j}} \varphi\left(\frac{\epsilon\left(y_{i t} \mid x_{i t}, k\right)-\mu_{m j}}{\omega_{m j}}\right)\right],
$$

with respect to $\mu_{m j}$ and $\omega_{m j}$. The solution can be written as weighted means and variances of the standardized residuals. 
- Compute ranks

$$
r\left(y_{i t} \mid x_{i t}, k\right)=F_{j}\left(\epsilon\left(y_{i t} \mid x_{i t}, k\right) \mid x_{i t}\right)
$$

and maximize

$$
\sum_{i \in \mathcal{S}_{j}} \sum_{k=1}^{K} \sum_{m=1}^{M} p_{j}\left(k \mid \mathbf{y}_{i}, \mathbf{e}_{i}, \mathbf{x}_{i}\right) \sum_{t / e_{i t}=e_{i, t+1}=1} \ln c\left[r\left(y_{i t} \mid x_{i t}, k\right), r\left(y_{i, t+1} \mid x_{i, t+1}, k\right) ; \exp \left(\gamma_{j} x_{i t}\right)-1\right]
$$

with respect to $\gamma_{j}$.

- Lastly, pooling all subpanels together regress the estimates of $j$-specific parameters on a constant, $j, j^{2}$, and $j^{3}$. Compute the restricted parameter estimates, and start a new E-step. Iterate until convergence.

A STATA program is available from the authors.

Acknowledgements. Comments from a coeditor and two anonymous referees have greatly improved this paper. We would also like to thank Manuel Arellano, Patrick Gagliardini, Laurent Gobillon, Christian Gouriéroux, Guy Laroque, David Margolis, and Fabien Postel-Vinay for their comments and suggestions. All remaining errors are our own. Stéphane Bonhomme gratefully acknowledges the financial support from the Spanish Ministry of Science and Innovation through the Consolider-Ingenio 2010 Project "Consolidating Economics". Jean-Marc Robin gratefully acknowledges the financial support from the Economic and Social Research Council for the ESRC Centre for Microdata Methods and Practice, "Cemmap" (grant reference RES-589-28-0001), and from the Direction de l'Animation de la Recherche, des Etudes et des Statistiques (DARES) of the French Ministère de l'Emploi et de la Solidarité (convention no. 4028).

\section{REFERENCES}

AABERGE, R., BJØRKLUND, A., JÄNTTI, M., PALME, M., PEDERSEN, P. J., SMITH, N. and WENNEMO, T. (2002), "Income Inequality and Income Mobility in the Scandinavian Countries Compared to the United States", Review of Income and Wealth, 48 (4), 443-469.

ALVAREZ, J., BROWNING, M. and EJRNÆS, M. (2002), "Modelling Income Processes with Lots of Heterogeneity" (CAM Working Paper, 2002-01, University of Copenhagen).

ARCIDIACONO, A. and JONES, J. (2003), "Finite Mixture Distributions, Sequential Likelihood and the EM Algorithm”, Econometrica, 71, 933-946.

ATTANASIO, O. and DAVIS, S. (1996), "Relative Wage Movements and the Distribution of Consumption", Journal of Political Economy, 104 (6), 1227-1262.

BAKER, M. and SOLON, G. (2003), "Earnings Dynamics and Inequality among Canadian Men, 1976-1992: Evidence from Longitudinal Income Tax Records", Journal of Labor Economics, 21, 289-321.

BLUNDELL, R. and PRESTON, I. (1998), "Consumption Inequality and Income Uncertainty", Quarterly Journal of Economics, 113 (2), 603-640.

BOWLUS, A. and ROBIN, J. M. (2004), “Twenty Years of Rising Inequality in U.S. Lifetime labour Income Values”, Review of Economic Studies, 71 (3), 709-742.

BURDETT, K. and MORTENSEN, D. T. (1998), "Wage Differentials, Employer Size and Unemployment”, International Economic Review, 39, 257-273.

BURKHAUSER, R. V. and POUPORE, J. G. (1997), "A Cross-National Comparison of Permanent Inequality in the United States and Germany", The Review of Economics and Statistics, 79 (1), 10-17.

BURKHAUSER, R. V., HOLTZ-EAKIN, D. and RHODY, S. E. (1997), "Labor Earnings Mobility and Inequality in the United States and Germany during the Growth Years of the 1980s", International Economic Review, 38 (4), 775-794.

CUTLER, D. M. and KATZ, L. F. (1992), "Rising Inequality? Changes in the Distribution of Income and Consumption in the 1980s", American Economic Review, 82 (3), 546-551.

FIELDS, G. S. (2005), "Does Income Mobility Equalize Longer-Term Incomes? New Measures of an Old Concept" (Working Paper, Cornell University).

FLINN, C. (2002), "Labour Market Structure and Inequality: A Comparison of Italy and the U.S.", The Review of Economic Studies, 69 (3), 611-645.

FRÉCHET, M. (1935), "Généralisations du Théorème des Probabilités Totales", Fundamenta Mathematicae, 25, 379-387.

GEWEKE, J. and KEANE, M. (2000), "An Empirical Analysis of Income Dynamics among Men in the PSID: 19681989”, Journal of Econometrics, 96, 293-356.

GEWEKE, J. and KEANE, M. (2007), "Smoothly Mixing Regressions”, Journal of Econometrics, 138, $252-290$.

GUVENEN, F. (2007), “An Empirical Investigation of Labor Income Processes” (NBER Working Paper No. 13394).

HAIDER, S. (2001), "Earnings Instability and Earnings Inequality of Males in the United States: 1967-1991", Journal of Labor Economics, 19 (4), 799-836.

HEATHCOTE, J., STORESLETTEN, K. and VIOLANTE, G. (2004), "The Cross-Sectional Implications of Rising Wage Inequality in the United States" (CEPR Discussion Paper No. 4296).

HOROWITZ, J. L. and MARKATOU, M. (1996), "Semiparametric Estimation of Regression Models for Panel Data", Review of Economic Studies, 63, 145-168. 
JOE, H. (1997), Multivariate Models and Dependence Concepts (London: Chapman \& Hall).

JOLIVET, G., POSTEL-VINAY, F. and ROBIN, J.-M. (2006), "The Empirical Content of the Job Search Model: Labor Mobility and Wage Dispersion in Europe and the U.S.," European Economic Review, 50 (4), 877-907.

KOTLARSKI, I. (1967), "On Characterizing the Gamma and Normal Distribution”, Pacific Journal of Mathematics, 20, 69-76.

KRUEGER, D. and PERRI, F. (2001), "Does Income Inequality Lead to Consumption Inequality? Empirical Findings and a Theoretical Explanation" (Mimeo).

MAASOUMI, E. and TREDE, M. (2001), "Comparing Income Mobility in Germany and the United States using Generalized Entropy Mobility Measures", The Review of Economics and Statistics, 83 (3), 551-559.

MARTIN, J. P. (1996), "Measures of Replacement Rates for the Purpose of International Comparisons: A Note", OECD Economic Survey, 26, 99-115.

MEGHIR, C. and PISTAFERRI, L. (2004), "Income Variance Dynamics and Heterogeneity", Econometrica, 72, 1-32.

MOFFITT, R. and GOTTSCHALK, P. (2002), "Trends in the Transitory Variance of Earnings in the U.S.", The Economic Journal, 112, C68-C73.

NELSEN, R. B. (1998), An Introduction to Copulas (New York: Springer Verlag).

PLACKETT, R. L. (1965), "A Class of Bivariate Distributions", Journal of the American Statistical Association, 60, 516-522.

POSTEL-VINAY, F. and ROBIN, J.-M. (2006), "Microeconometric Search-Matching Models and Matched EmployerEmployee Data", in R. Blundell, W. Newey and T. Persson (eds.) Advance in Economics and Econometrics, Theory and Applications: Ninth World Congress (Cambridge: Cambridge University Press).

SHORROCKS, A. (1978), "Income Inequality and Income Mobility", Journal of Economic Theory, 19, 376-393.

SKLAR, A. (1959), "Fonctions de Répartition à $n$ Dimensions et leurs Marges", Publications de Institut de Statistique de L'Université de Paris, 8, 229-231.

VAN DEN BERG, G. J. and RIDDER, G. (1998), "An Empirical Equilibrium Search Model of the Labor Market", Econometrica, 66, 1183-1221.

VAN KERM, P. (2004), "What Lies Behind Income Mobility? Reranking and Distributional Change in Belgium, Western Germany and the U.S.A.", Economica, 71 (282), 223-239. 